Linköping Studies in Science and Technology,

Thesis No. 1689

\title{
Novel reagentless electrodes for biosensing
}

Alina Sekretaryova

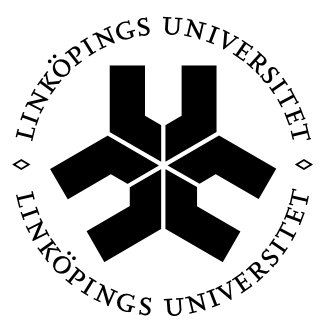

Linköping University

INSTITUTE OF TECHNOLOGY

Division of Chemical and Optical Sensor Systems

Department of Physics, Chemistry, and Biology (IFM) Linköping University, SE-581 83 Linköping, Sweden 
(c)Alina Sekretaryova, 2014

Novel reagentless electrodes for biosensing

ISBN 978-91-7519-187-4

ISSN 0280-7971

Linköping studies in science and technology

Dissertation No. 1689

Printed in Sweden by LiU-Tryck, Linköping, Sweden, 2014 


\section{ABSTRACT}

Analytical chemical information is needed in all areas of human activity including health care, pharmacology, food control and environmental chemistry. Today one of the main challenges in analytical chemistry is the development of methods to perform accurate and sensitive rapid analysis and monitoring of analytes in 'real' samples. Electrochemical biosensors are ideally suited for these applications.

Despite the wide application of electrochemical biosensors, they have some limitations. Thus, there is a demand on improvement of biosensor performance together with a necessity of simplification required for their mass production. In this thesis the work is focused on the development of electrochemical sensors with improved performance applicable for mass production, e.g. by screen printing.

Biosensors using immobilized oxidases as the bio-recognition element are among the most widely used electrochemical devices. Electrical communication between redox enzymes and electrodes can be established by using natural or synthetic electron carriers as mediators. However, sensors based on soluble electronshuttling redox couples have low operational stability due to the leakage of water-soluble mediators to the solution. We have found a new hydrophobic mediator for oxidases - unsubstituted phenothiazine. Phenothiazine and glucose oxidase, lactate oxidase or cholesterol oxidase were successfully co-immobilized in a sol-gel membrane on a screen-printed electrode to construct glucose, lactate and cholesterol biosensors, respectively. All elaborated biosensors with phenothiazine as a mediator exhibited long-term operational stability. A kinetic study of the mediator has shown that phenothiazine is able to function as an efficient mediator in oxidase-based biosensors.

To improve sensitivity of the biosensors and simplify their production we have developed a simple approach for production of graphite microelectrode arrays. Arrays of microband electrodes were produced by screen printing followed by scissor cutting, which enabled the realization of microband arrays at the cut edge. The analytical performance of the system is illustrated by the detection of ascorbic acid through direct oxidation and by detection of glucose using a phenothiazine mediated glucose biosensor. Both systems showed enhanced sensitivity due to improved mass transport. Moreover, the developed approach can be adapted to automated electrode recovery.

Finally, two enzyme-based electrocatalytic systems with oxidation and reduction responses, respectively, have been combined into a fuel cell generating a current as an analytical output (a so-called self-powered biosensor). This was possible as a result of the development of the phenothiazine mediated enzyme electrodes, 
which enabled the construction of a cholesterol biosensor with self-powered configuration. The biosensor generates a current when analyte (cholesterol) is added to the cell. The biosensor has been applied for whole plasma analysis.

All developed concepts in the thesis are compatible with a wide range of applications and some of them may even be possible to realize in a fully integrated biosensor unit based on printed electronics. 


\section{ACKNOWLEDGMENTS}

First of all, I would like to thank my supervisor Mats Eriksson for his excellent supervision and guidance. I would also like to thank my co-supervisors Mikhail Vagin and Prof. Anthony Turner for scientific discussions and support.

Thanks to Anna Maria Uhlin and Anette Andersson for taking care of all administrative issues.

I feel thankful to Stefan Klinström, director of Forum Scientium, for great opportunity to develop scientific and social contacts and to enjoy time more during my $\mathrm{PhD}$ period.

I am also thankful to all present and former colleagues in the Chemical and Optical Sensor Systems group and Biosensors and Bioelectronics Center for making my working days pleasant. My special thanks go to Valerio Beni and Hirak Patra.

And finally, Onur Parlak, thank you for always taking care of me, for your love and your patience. You always encourage me to be a better person. 



\section{LIST OF PUBLICATIONS}

The licentiate thesis is based on the following papers:

I. Reagentless biosensor based on glucose oxidase wired by the mediator freely diffusing in enzyme containing membrane

A.N. Sekretaryova, D.V. Vokhmyanina, T.O. Chulanova, E.E. Karyakina, A.A. Karyakin.

Analytical Chemistry 2012, 84, 1120-1223.

II. Unsubstituted phenothiazine as a superior water-insoluble mediator for oxidases

A.N. Sekretaryova, M.Yu. Vagin, V. Beni, A.P.F. Turner, A.A. Karyakin. Biosensors and Bioelectronics 2014, 53, 275-282.

III. Arrays of screen-printed graphite microband electrodes as a versatile electroanalysis platform

M.Yu. Vagin, A.N. Sekretaryova, R.S. Reategui, I. Lundstrom, F. Winquist, M. Eriksson.

ChemElectroChem 2014, 1, 755-762.

IV. Cholesterol self-powered biosensor

A.N. Sekretaryova, V. Beni, M. Eriksson, A.A. Karyakin, A.P.F. Turner and M.Yu. Vagin.

Analytical Chemistry 2014, 86, 9540-9547.

\section{My contributions}

Paper I: I performed most of the experimental works, data evaluation and interpretation. I wrote experimental section and part of the results and discussion.

Papers II, IV: I performed all experimental work, data evaluation and interpretation. I wrote the first versions of the manuscript.

Paper III: I performed part of the experimental work and data evaluation (detection of ascorbic acid and glucose biosensor, optical microscopy). 
Related publications, not included in this licentiate thesis:

I. M.Yu. Vagin, A.N. Sekretaryova, R.S. Reategui, I. Lundstrom, A.P.F. Turner, M. Eriksson. Screen-printed graphite microband for electroanalysis, Conference paper, Abstract, 15th International Conference on Electroanalysis (ESEAC), Malmö, Sweden, 11-15 June 2014.

II. A.N. Sekretaryova, V. Beni, M. Eriksson, A.A. Karyakin, A.P.F. Turner and M.Yu. Vagin. A higly sensitive and self-powered cholesterol biosensor. Conference paper, Abstract, $24^{\text {th }}$ Anniversary World Congress on Biosensors - Biosensors 2014, Melbourne, Australia, 27-30 May 2014.

III. M.Yu. Vagin, A.N. Sekretaryova, R.S. Reategui, I. Lundstrom, A.P.F. Turner, M. Eriksson. Screen-printed graphite microbands as a versatile biosensor platform. Conference paper, Abstract, 24 $4^{\text {th }}$ Anniversary World Congress on Biosensors - Biosensors 2014, Melbourne, Australia, 27-30 May 2014.

IV. A.N. Sekretaryova, M.Yu. Vagin, M. Eriksson, A.A. Karyakin, A.P.F. Turner. Electrochemical sensing platform based on solgel/phenothiazine/enzyme composite films. Conference paper, Abstract, Advanced Materials World Congress (AMWC 2013), İzmir, Turkey, 1619 September 2013.

V. A.N. Sekretaryova, A.A. Karyakin. Reagentless Lactate Biosensor Free of Covalent Mediator Linking. Conference paper, Abstract, $63^{\text {rd }}$ Annual Meeting of the International Society of Electrochemistry, Prague, Czech Republic, 19-24 August 2012.

VI. A.N. Sekretaryova, A.A. Karyakin. Reagentless Second Generation Biosensor Free of Covalent Mediator Linking. Conference paper, Abstract. $5^{\text {th }}$ International Workshop 'Surface Modification for Chemical and Biochemical Sensing (SMCBS 2011), Lochow, Poland, 4-8 November 2011. 


\section{CONTENTS}

ABBREVIATIONS .........................................................................................

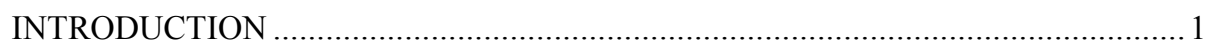

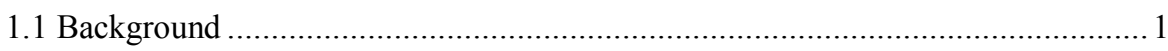

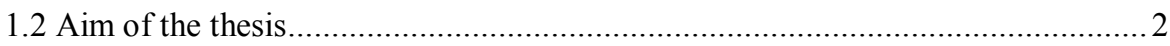

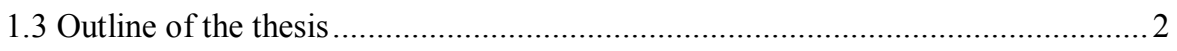

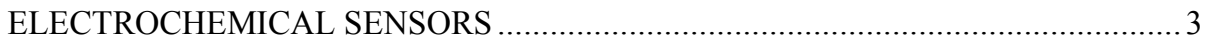

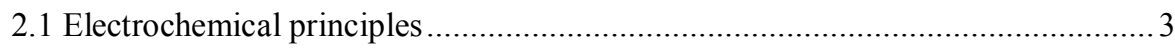

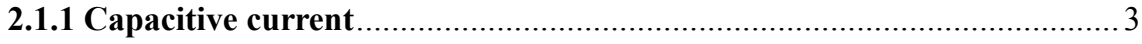

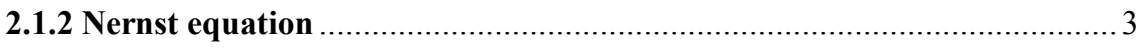

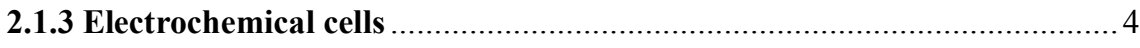

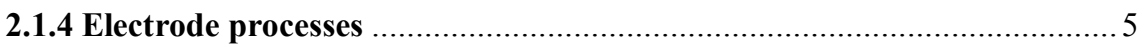

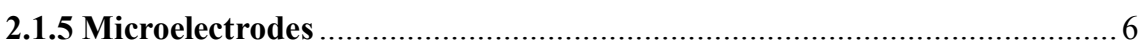

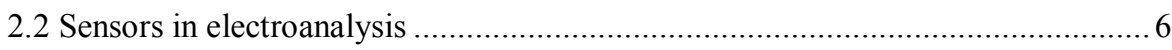

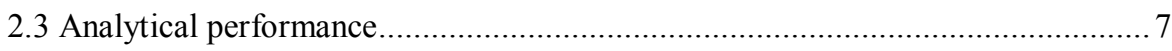

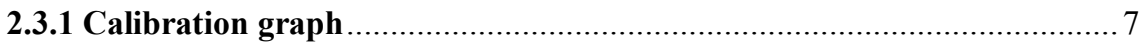

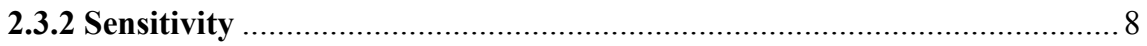

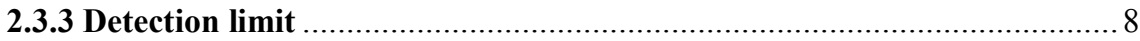

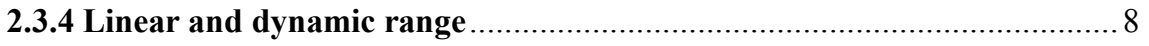

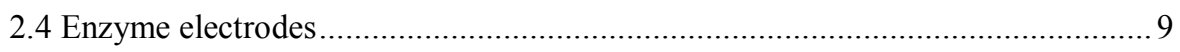

2.4.1 'First-generation' biosensors ............................................................ 9

2.4.2 'Second-generation' biosensors ....................................................... 10

2.4.3 'Third-generation' biosensors............................................................. 10

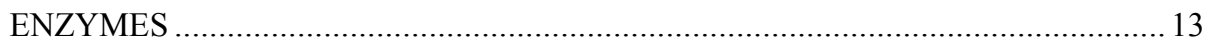

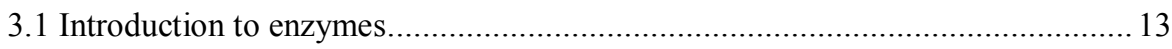

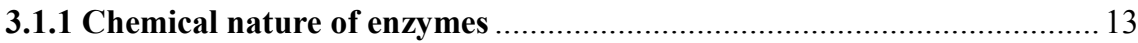

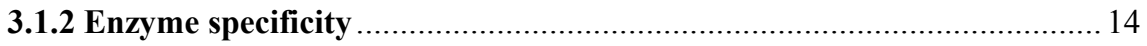

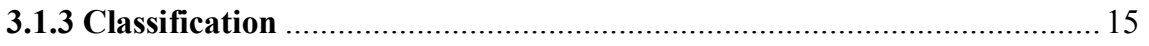

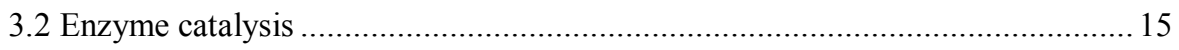

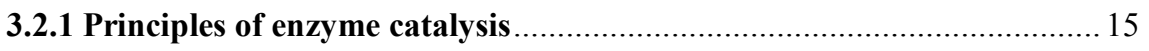

3.2.2 Equations of enzyme kinetics ............................................................. 16

3.2.3 Factors affecting enzyme activity ................................................... 17

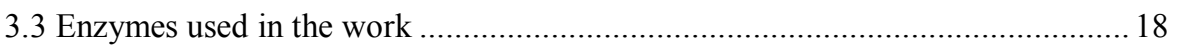

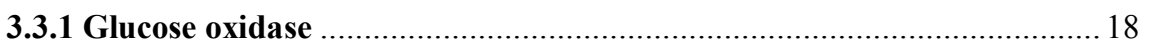

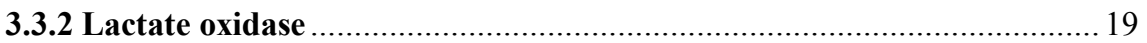




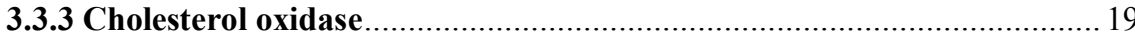

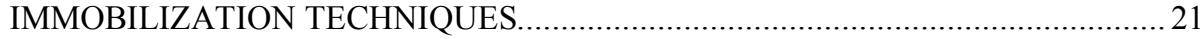

4.1 Overview of the main immobilization techniques .......................................... 21

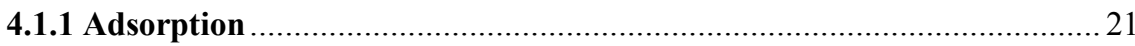

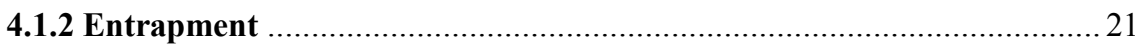

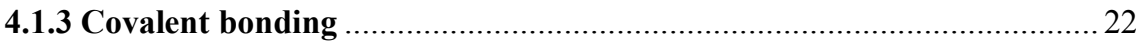

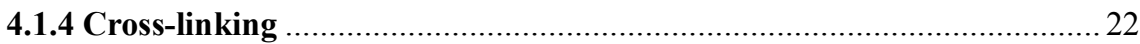

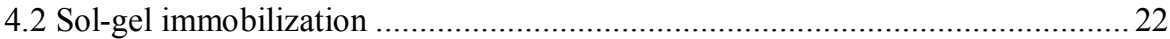

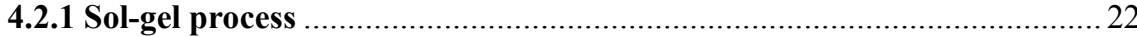

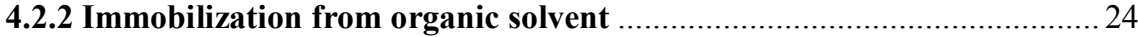

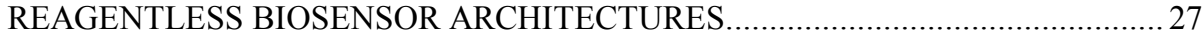

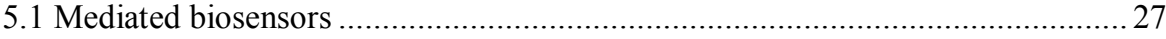

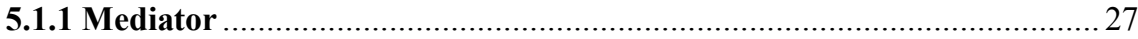

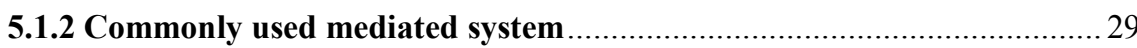

5.1.3 Azines as mediators for oxidases ................................................... 29

5.1.4 Enzyme and mediator co-immobilization........................................... 30

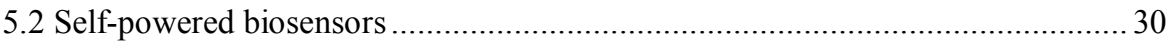

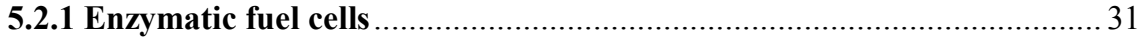

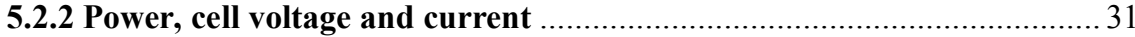

5.2.3 Important examples of self-powered biosensors ................................. 32

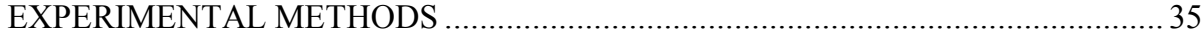

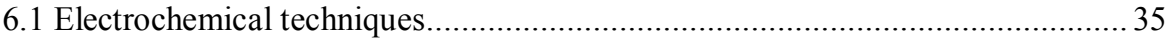

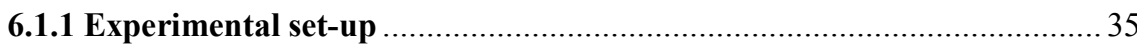

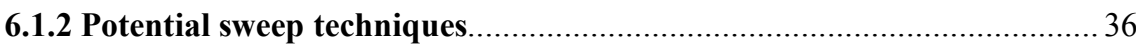

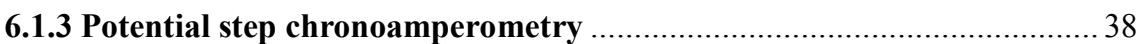

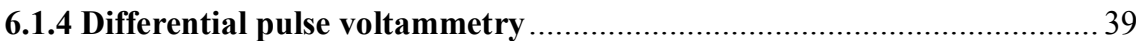

6.1.5 Measurements on hydrodynamic electrodes .......................................... 40

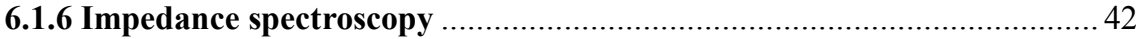

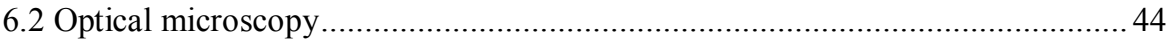

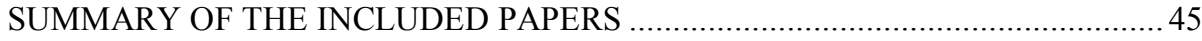

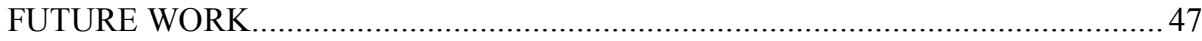

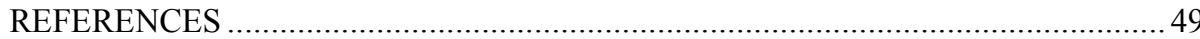




\section{ABBREVIATIONS}

$\begin{array}{ll}\text { APTEOS } & \text { 3-aminopropyl-triethoxysilane } \\ \text { BFC } & \text { biofuel cell } \\ \text { CCE } & \text { carbon cloth electrode } \\ \text { ChOx } & \text { cholesterol oxidase } \\ \text { CV } & \text { cyclic voltammetry } \\ \text { DPV } & \text { differential pulse voltammetry } \\ \text { FAD } & \text { flavin adenine dinucleotide } \\ \text { FMN } & \text { flavin mononucleotide } \\ \text { GCE } & \text { glassy carbon electrode } \\ \text { GOx } & \text { glucose oxidase } \\ \text { LOx } & \text { lactate oxidase } \\ \text { LSV } & \text { linear sweep voltammetry } \\ \text { MA } & \text { microbands array } \\ \text { OCP } & \text { open circuit potential } \\ \text { PTZ } & \text { unsubstituted phenothiazine } \\ \text { RDE } & \text { rotating disk electrode } \\ \text { SPE } & \text { screen-printed electrode } \\ \text { TEOS } & \text { tetraethoxysilane } \\ \text { TMOS } & \text { tetramethoxysilane } \\ \end{array}$





\section{1 \\ INTRODUCTION}

\subsection{Background}

Today one of the main challenges in analytical chemistry is the development of methods to perform rapid analyses and monitoring of analytes of interest outside the laboratory. These methods must be sensitive and accurate, and able to determine various substances with different properties in real samples. Electrochemical sensors for the measurement of analytes of interest in medicine, pharmacology, food control and environmental monitoring are ideally suited for these applications, due to their high sensitivity and selectivity, portable size, rapid response time and relatively low cost. Such capabilities have already made a significant impact on decentralized clinical analysis. ${ }^{1}$ Yet, despite their great potential for environmental monitoring, ${ }^{2}$ broad applications of electrochemical sensors for pollution control are still in their infancy.

Sensors are devices that convert chemical or physical information into a read-out signal. Being one of the types of chemical sensors, biosensors are self-contained and integrated devices with specific quantitative or semi-quantitative analytical information and are based on a biological recognition element spatiallyintegrated with the transducer, which converts recognition evidence into a readout signal. ${ }^{3}$ Enzymes, antibodies, receptors or whole cells can be used as a biorecognition element in biosensors. Depending on the read-out principle used, the biosensors can be of many types, such as optical, piezoelectric, thermal, conductometric, electrochemical etc. The thesis is focused on electrochemical biosensors.

The modern concept of biosensing electroanalysis has represented a rapidly expanding field of instrument design since 1962, when Clark and Lyons invented the first electrochemical biosensor, known as the 'enzyme electrode', using the enzyme glucose oxidase (GOx) immobilized on an amperometric electrode to measure dissolved oxygen. ${ }^{4}$ From that time biosensors using immobilized enzymes as the bio-recognition element have become one of the most widely investigated devices for both fundamental research and commercialization. ${ }^{5,6}$ In general, electrochemical biosensors have shown an extensive evolution up to specific, portable, simple-to-operate tools of fundamental research, as well as of 
applied analysis for foodstuff control and for security, clinical and environmental applications.

\subsection{Aim of the thesis}

Despite the wide application of electrochemical sensors, they have some limitations: electrochemically active interferences in the sample, weak long-term stability and slow electron-transfer. Thus, there is a demand on improvement of biosensor performance together with a necessity of simplification required for mass production. There are different ways to improve the biosensor usefulness, such as development of electrode materials, new techniques for the immobilization of the bio-recognition element, microfabrication and screen printing technology.

The aim of my research is development of new reagentless analytical devices with advanced performance suitable for mass production. My first goal is the creation of a technological strategy that allows the functional control of both oxidation and reduction electrode processes on the same biocatalyst. The second goal is the elaboration of a protocol for scalable production of microsensors as an advanced and versatile sensing platform. The third goal is the fabrication of an advanced analytical device available for both specific quantification and power generation.

\subsection{Outline of the thesis}

The licentiate thesis deals with development of reagentless electrodes for biosensing. The thesis is divided into several chapters. The thesis starts with some introductory information about electrochemical sensors and the main problems of their constructions in Chapter 2. Chapters 3 and 4 present information about the recognition part of the sensor - enzymes and ways of their immobilization on electrode surfaces. Chapter 5 gives the background to the different projects included in the thesis. Chapter 6 includes information about experimental methods used in the thesis. Finally, a summary of the work and future perspectives are given in Chapters 7 and 8 . 


\section{2}

\section{ELECTROCHEMICAL SENSORS}

The goal of this chapter is to provide basic knowledge on electrochemistry and electrochemical sensors of importance for the research presented.

\subsection{Electrochemical principles}

Being the application of electrical measurements for chemical science, electrochemistry is the scientific area dedicated to the studies of charge transfer processes at interfaces. The charge transfer process with transfer of electrons can be presented as follows:

$O+n e^{-} \leftrightarrow R$

where $\mathrm{O}$ - oxidized species, $\mathrm{R}$ - reduces species, $\mathrm{n}-$ amount of electrons transferred.

\subsubsection{Capacitive current}

The electrode has some charge density which occurs due to an excess or deficiency of electrons at the electrode surface. In order to keep electrical neutrality of the interface the electrolyte ions and solvent dipoles have to redistribute in a such way that the solution near to the electrode surface possesses an equal but opposite charge. This layer near to the interface is called the electrical double layer. The charge separation in the double layer creates a capacitor associated with a potential difference across the interface and produces a capacitive current $\left(\mathrm{I}_{\mathrm{c}}\right)$ :

$I_{c}=C_{d l} \frac{d E}{d t}$

where $\mathrm{C}_{\mathrm{dl}}-$ double layer capacitance. $\mathrm{I}_{\mathrm{c}}$ contributes to the total current measured in the experiment but it is not related to the charge transfer process. ${ }^{7}$

\subsubsection{Nernst equation}

The dependence of the electrode potential for the electrochemical reaction (2.1) on the activities ('effective concentrations') of the oxidized $\left(a_{0}\right)$ and reduced $\left(a_{R}\right)$ species can be described by the Nernst equation: ${ }^{7}$ 


$$
E=E^{0}+\frac{R T}{n F} \ln \frac{a_{O}}{a_{R}}
$$

where $\mathrm{R}$ - the gas constant $\left(8.3144621(75) \mathrm{J} \mathrm{mol}^{-1} \mathrm{~K}^{-1}\right), \mathrm{T}$ - thermodynamic temperature, F - Faraday constant $\left(9.64853399(24) \times 10^{4} \mathrm{C} \mathrm{mol}^{-1}\right)$. $\mathrm{E}_{0}-$ standard electrode potential of the electrochemical reaction which as defined as the electrode potential of reaction (2.1) when $\mathrm{a}_{0}=\mathrm{a}_{\mathrm{R}}=1 .^{7}$

In electroanalytical experiments, it is usually more convenient to deal with concentrations (C) of the electroactive species rather than their activities, as a generalized quantitative parameter developed for non-ideal chemical systems. The activity coefficient $\gamma$ relates the concentration of an ion to its activity according to following equation:

$a=\gamma C$

Thus, the Nernst equation is more often used with concentrations: ${ }^{8}$

$E=E^{0^{\prime}}+\frac{R T}{n F} \ln \frac{C_{O}}{C_{R}}$

where $\mathrm{E}^{0}$ is called the formal potential.

$$
E^{0^{\prime}}=E^{0}+\frac{R T}{n F} \ln \frac{\gamma_{O}}{\gamma_{R}}
$$

\subsubsection{Electrochemical cells}

Electrochemical sensors described in this chapter are based on measurements of the electrode potential-current dependence, where the current is determined by the rate of an electrochemical reaction on a so called 'working electrode'. According to the law of energy conservation, the same current must flow through a counter or auxiliary electrode. Thus, an electrochemical experiment requires a so called 'electrochemical cell', a vessel with electrolyte in which two independent electrodes are placed and linked with a measuring device through the external wires to form an electrical circuit. Thus the chemical processes occurring in the cell might be studied and controlled by the measuring device. If the redox reaction in the cell can occur spontaneously, the cell is called a galvanic cell. If the redox reaction in the cell occurs as a result of applied chemical energy, the cell is called an electrolytic cell.

In electrochemical experiments the reaction on the auxiliary electrode is usually unknown and is not rate-determining. Therefore the dependence of the electrode potential-current on this electrode can not be used for determination of thermodynamic parameters. Hence, electrochemical experiments require a third electrode, the so called 'reference electrode'. Current is not flowing through the reference electrode and the electrode is made in such way that its potential is 
constant and stable. Since the potential of the working electrode is always measured relative to the reference electrode, the electrochemical reaction on the reference electrode can theoretically be considered as a counterpart. The potential of the reference electrode is measured relative to the standard hydrogen electrode (SHE) potential, which is chosen as the zero level. ${ }^{9}$

\subsubsection{Electrode processes}

In the description of the electrode processes, it is necessary to consider the transport of species to the electrode surface as well as the electrode reaction itself. The transport can be provided by diffusion, convection or migration. In electroanalytical experiments, the conditions are chosen in such way that only transport by diffusion occurs. This leads to the scheme of electrode processes illustrated in Fig. 2.1.

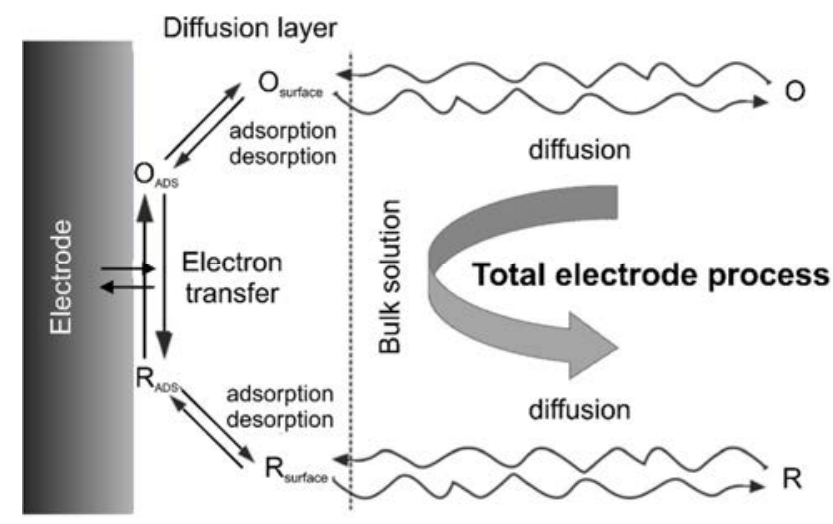

Figure 2.1. Scheme of electrode processes.

It is usually possible to divide electrode processes in processes controlled by diffusion and processes controlled by kinetics of the electrode reaction. This means that in the first case the rate of mass transport to the electrode surface is the slowest step of the electrode processes and it determines the rate of the overall process. In the second case, diffusion is much faster than the electrode reaction and the rate of the process is determined by the electrode kinetics. Such considerations allow significant simplifications of the equations describing the electrode processes.

The electrode processes are often controlled by diffusion since the electrode reaction is usually very fast compared to the diffusion. Currents that are not controlled by diffusion (steady-state currents) can be achieved with hydrodynamic electrodes (see section 6.1.5) and with microelectrodes. 


\subsubsection{Microelectrodes}

Microelectrodes are electrodes that have at least one dimension smaller than $100 \mu \mathrm{m}$ and thus have special characteristics which are directly related to their size. Reduction of size leads to lower capacitive currents and convergent diffusion (Fig. 2.2) compared to planar diffusion at macroelectrodes which allows to attain steady-state currents within short time.
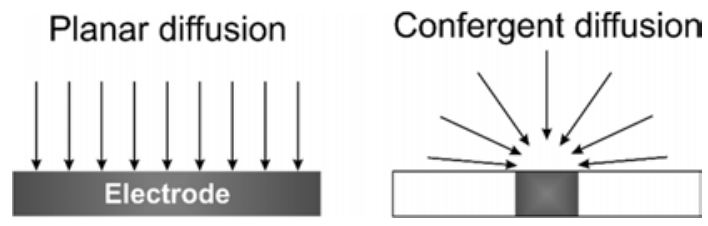

Figure 2.2. Illustration of planar diffusion on a macroelectrode $v s$ convergent diffusion on a microelectrode.

In recent years microelectrodes have been routinely employed in analytical and physiological applications due to their many advantageous properties. These include their small size, allowing to use smaller sample volumes and making possible their application for in vivo measurements, low background currents due to reduced surface area, high current density arising from enhanced mass transport to the electrode surface. ${ }^{10}$ However, single microelectrodes produce small currents, which are difficult to detect with conventional electrochemical equipment. This problem can be solved by using an assembly of microelectrodes, with each microelectrode independent of its neighbors. With appropriate design, such an assembly may show all the useful properties of a single microelectrode while generating higher currents. ${ }^{11}$ Arrays of microelectrodes produced by screen printing technology were used for the biosensor construction in Paper III.

\subsection{Sensors in electroanalysis}

Electroanalysis is the application of electrochemistry for analytical purposes. Electrochemical sensors and biosensors are extremely important areas of electroanalysis.

A chemical sensor is a device that provides real-time reliable information about the chemical composition of its surrounding environment. It consists of a chemical or biological recognition layer and a transducer. ${ }^{12}$ In case of electrochemical sensors the electrode is used as a transducer. Electrochemical sensors are based on potentiometric, voltammetric, or conductivity measurements. The scheme of electrochemical sensors is shown in Fig. 2.3. 


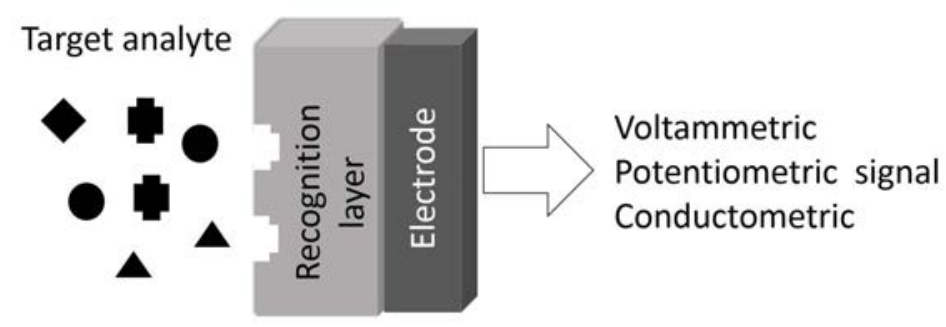

Figure 2.3. Electrochemical biosensors: biorecognition and signal transduction (reproduced with modifications). ${ }^{12}$

Voltammetric sensors depend on the recording of current-potential profiles. A special case of voltammetric sensors is amperometric sensors. Amperometric sensors that this thesis deals with are based on the monitoring of currents produced by electroactive species involved in the electrode process. The potential of the working electrode is maintained at a fixed value (relative to a reference electrode) and the current is monitored as a function of time. The resulting current is a direct measure of the rate of the electron transfer reaction driven by the applied potential and it is proportional to the concentration of the target analyte. ${ }^{13}$

In potentiometric sensors, the analytical information is obtained from the monitoring of a potential difference at equilibrium related to the electrode process. The signal is proportional to the concentration of species generated or consumed in the recognition event. Usually potentiometric sensors are slower than amperometric. ${ }^{13}$

In conductometric sensors, changes in conductivity are monitored. A drawback of the conductometric transducer is the strong dependence of the response on buffer capacity and on number of ions presented in solution. ${ }^{13}$

\subsection{Analytical performance}

Efficiency and applicability of the sensor in different areas depend on its analytical performance. There are many parameters to describe sensor performance but I would like to discuss only those used for amperometic sensor characterization in this thesis, i.e. calibration graph (curve), sensitivity, detection limit, linear and dynamic range (Fig. 2.4).

\subsubsection{Calibration graph}

To obtain quantitative information about the concentration of the analyte of interest one should know the dependence of the current signal on the concentration of the analyte in the same system that would be used for a test sample analysis. The results are used to plot a calibration graph (or calibration 
plot, or calibration curve) which is then used to determine the analyte concentrations in test samples by interpolation. ${ }^{14}$

\subsubsection{Sensitivity}

In analytical techniques, sensitivity is defined as the slope of the calibration graph. ${ }^{15}$ If the curve is not linear then of course sensitivity will be a function of analyte concentration (or amount). If sensitivity is to be a unique performance characteristic, it must depend only on the chemical measurement process, not upon scale factors.

\subsubsection{Detection limit}

Detection limit (or limit of detection) is a theoretical term that may be described as the concentration of the analyte that gives an analytical signal significantly higher than the background noise. There is still not full agreement between researchers how to calculate the detection limit. In all my publications included in the thesis I have calculated detection limit as the standard deviation of the baseline current multiplied by three and divided by the sensitivity. ${ }^{16}$

\subsubsection{Linear and dynamic range}

The linear range is the range of concentrations of the analyte within the working range where the measured current is directly proportional to the concentration. The dynamic range is the range of analyte concentrations over which there is a measurable sensitivity to the analyte. ${ }^{17}$
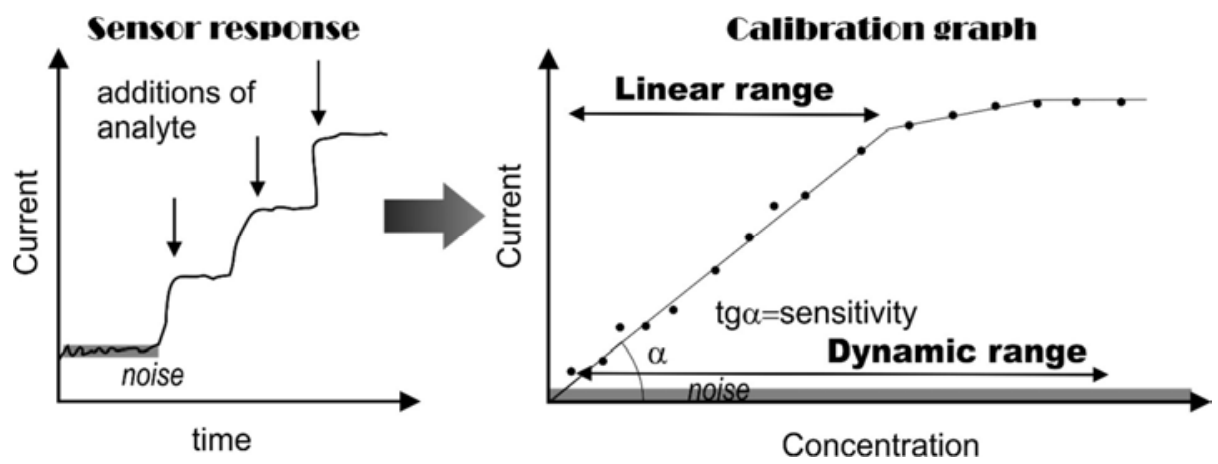

Figure 2.4. Illustration of determination of analytical performances from amperometric sensor response. 


\subsection{Enzyme electrodes}

A biosensor is a device incorporating a biological sensing element. ${ }^{18}$ Enzymes, antibodies, receptors or whole cells can be used as a bio-recognition element in biosensors. Enzyme electrodes have the longest tradition in the field of biosensors. ${ }^{4}$ Such devices are usually prepared by attaching an enzyme layer to the electrode surface, which monitors changes occurring as a result of the biocatalytic reaction.

Analytes that can be measured by enzyme electrodes can be divided into two groups: analytes measured due to the increase of enzymatic product concentration and analytes that inhibit the enzyme activity and decrease product formation. The latter type is called 'biosensors based on enzyme inhibition'. The main applications of this type of biosensors is environmental analysis. ${ }^{19}$

Biosensors with analyte metabolized by the enzyme can be classified according to three so-called 'generations' (Fig. 2.5) ${ }^{20}$, which will be illustrated by oxidases.

\subsection{1 'First-generation' biosensors}

First-generation biosensors are based on the detection of, either the increase of a product of an enzymatic reaction or the decrease of the enzyme substrate. Changes in concentration of a natural enzyme substrate participating in an enzymatic reaction can be also monitored. In all these cases, it is necessary that the measured compound is electrochemically active.

Oxidase-based 'first generation' biosensors measure the concentrations of oxygen as a natural oxidizing substrate or hydrogen peroxide as a product: ${ }^{21}$

$$
\begin{aligned}
& \text { substrate }+ \text { enzyme }_{o x} \rightarrow \text { enzume }_{\text {red }}+\text { product } \\
& \text { enzyme }_{\text {red }}+\mathrm{O}_{2} \rightarrow \text { enzyme }_{o x}+\mathrm{H}_{2} \mathrm{O}_{2}
\end{aligned}
$$

Here, the increasing concentration of $\mathrm{H}_{2} \mathrm{O}_{2}$ or the decrease in $\mathrm{O}_{2}$ concentrations can be electrochemically detected in order to monitor analyte concentration.

First-generation biosensors have several drawbacks. Firstly, the amperometric measurements of hydrogen peroxide and oxygen require application of high potential at which the impact of interferences present in biological or environmental samples is significant. Secondly, since this type of oxidase-based biosensors use oxygen as a natural electron acceptor, their response depend on oxygen concentrations which can fluctuate giving rise to errors. ${ }^{20}$

The first invented biosensor was a first generation biosensor using glucose oxidase (GOx) as a bio-recognition element. ${ }^{4}$ In this biosensor GOx had been immobilized onto an oxygen-sensitive amperometric detector (known now as the 
Clark's electrode) via a semi-permeable membrane. As a result of enzymatic oxidation of glucose, catalyzed by GOx, the concentration of oxygen in the solution decreases, which is monitored by the Clark's electrode.

\subsection{2 'Second-generation' biosensors}

The mentioned drawbacks of the first-generation biosensors can be partially overcome by replacing oxygen with a synthetic electron acceptor - a mediator. The mediator transfers electrons, generated or consumed during the enzymatic reaction between the enzyme and the electrode. This type of biosensors, also called 'mediated biosensors', is the most commonly used configuration and will be discussed in detail in section 5.1 Mediated biosensor of the thesis.

\subsection{3 'Third-generation' biosensors}

Third-generation biosensors are based on direct electron transfer between the enzyme and the electrode surface. The absence of a mediator is the main advantage of such biosensors providing high efficiency and simple design. However, direct electron transfer between redox enzyme and electrode close to the electrode surface can be very slow due to the insulating protein shell, shielding the enzyme active site (see section 3.1.1). Therefore, from 1060 known oxidoreductases ${ }^{22}$ only $50-60$ are able to transfer electrons directly between the active site and the electrode surface ${ }^{23}$ due to the close distance, no longer then 10 $-15 \AA \AA^{20}$

Efficiency of direct electron transfer depends not only on the distance between the active site of the enzyme and the electrode, but also on the properties of the electrode material and on the immobilization technique. Even if the enzyme molecule is immobilized on the electrode surface, it can be oriented in such a way that direct electron transfer is not possible due to a longer distance between the active site and the electrode compared to the ideal orientation. ${ }^{20}$

Thus, although third-generation biosensors are advantageous compared to the two other generations, they are still not widely used due to problems in their construction and the restricted number of enzymes available for direct electron transfer. 


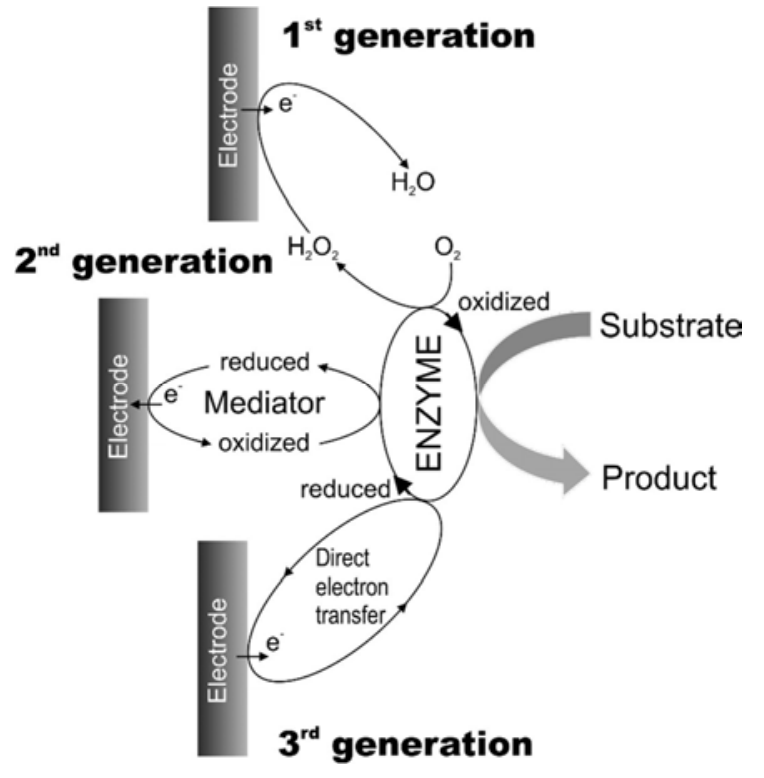

Figure 2.5. Representation of three different amperometric biosensor generations. 



\section{3 \\ ENZYMES}

The enzyme is, of course, an essential part of an enzyme electrode. To improve the performance of such electrodes we need to understand the working principles of enzymes and factors influencing their kinetics. This chapter contains basic information about enzymes, principles of enzyme catalysis and details about catalytic specificity and activity of enzymes used in the work presented in this thesis.

\subsection{Introduction to enzymes}

Enzymes are (typically) proteins, which have the ability to significantly increase reaction rates (on the order of $10^{6}$ to $10^{18}$ ) of their substrates. The word 'enzyme' (en=in, zyme=yeast) was invented by German physiologist Wilhem Kuhne in $1877.24,25$

\section{.1.1 Chemical nature of enzymes}

Since 1926, when the American biochemist James Sumner crystalized urease, it has been known that most of the enzymes are proteins. Enzymes are mainly globular proteins - protein molecules where the tertiary structure has given the molecule a generally rounded shape ('enzyme globule').

Enzyme molecules usually consist of an apoenzyme (a protein part) and a cofactor (non-protein part required for enzyme catalytic activity). The entire active complex is called holoenzyme. Enzyme cofactors can be divided in two groups:

1. Organic cofactors:

a) Coenzymes - organic substances loosely attached to the protein part;

b) Prostetic groups - organic substances strongly attached to the protein part;

2. Inorganic cofactors - metal ions. ${ }^{26}$

The enzyme molecule contains one or more so called 'active sites', where the substrate molecule binds and the reaction occurs. The active site occupies a small portion of the enzyme molecule and has a well-defined 3D structure. The active site has two tasks: catalytic action and specificity. ${ }^{25}$ 


\subsubsection{Enzyme specificity}

One of the properties of enzymes, that make them so widely used in biosensing, is the specificity to the catalyzed reaction. Enzyme specificities to their substrates vary from biomolecule to biomolecule. ${ }^{25}$ There are enzymes with rather wide specificity catalyzing reactions of some group of compounds as for example laccase catalyzing oxidation of phenols, diamines and also some inorganic ions. ${ }^{27}$ Many enzymes are very specific showing even stereochemical specificity, as for instance lactate oxidase used in my work and described below.

There are two theories that describe enzyme specificity: the Lock-and-key model and the Induced Fit model (Fig. 3.1). The lock-and-key theory was proposed in the 1890 s by Fisher. ${ }^{24}$ According to this theory, the active site has a rigid structure similar to a lock. A substrate has a complementary structure as a key. According to another theory proposed in 1958 by Koshland, structures of the active site and the substrate are not complementary. The binding of the substrate to the active site induces changes in the 3-D structure of the active site to make it fit to the substrate structure. After release of the products of the reaction, the active site returns to its initial configuration. ${ }^{24}$ The specificity of enzymes with single substrates can be explained using the lock-and-key model. However, not all experimental facts for more complicated enzymes can be explained using this theory. In such cases, the induced fit model is applied.

\section{Lock-and-key theory}

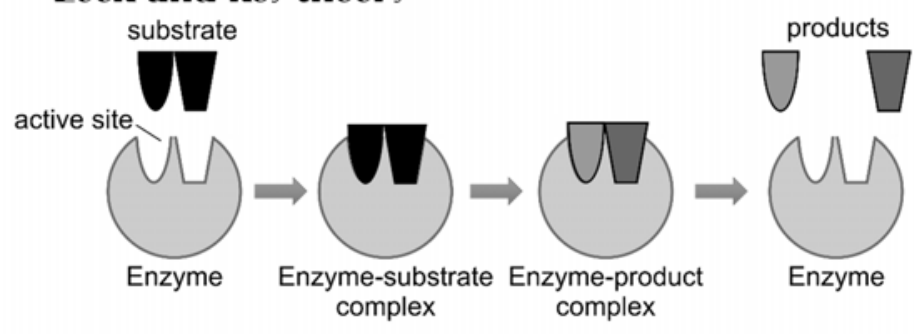

\section{Induced fit theory}

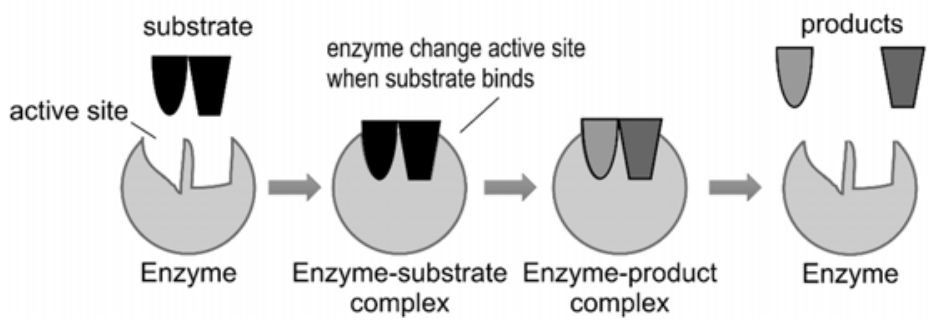

Figure 3.1. Illustration of the two theories of enzyme binding. 


\subsubsection{Classification}

There are six main classes of enzymes distinguished according to the reaction they catalyze: ${ }^{24}$

- Oxidoreductases - catalyzes redox reactions;

- Transferases - catalyzes transfer of functional groups;

- Hydrolases - catalyzes hydrolysis of substrates;

- Lyases - catalyzes removal of groups other than hydroxyl;

- Isomerases - catalyzes inter-molecular rearrangements;

- Ligases - catalyzes the union of two molecules.

Each enzyme is represented by 4 numbers in databases. The first number indicates class, the second number - subclass, the third number - subsubclass and the fourth number - serial number in the subsubclass. ${ }^{24,25}$

The oxidases used in Papers I-IV are oxidoreductases that catalyze redox reactions involving molecular oxygen, $\mathrm{O}_{2}$.

\subsection{Enzyme catalysis}

\subsubsection{Principles of enzyme catalysis}

The enzymatic reaction can be described as proposed by Arrhenius in 1888:

$$
E+S \underset{k_{-1}}{\stackrel{k_{1}}{\rightleftharpoons}} E S \stackrel{k_{2}}{\longrightarrow} E+P
$$

where E - enzyme, S - substrate, P - product and ES - enzyme-substrate complex. The enzyme, being a catalyst, speeds up the reaction without being consumed by the process. It lowers the Gibbs energy of activation (Fig. 3.2) by changing the reaction mechanism. ${ }^{25}$

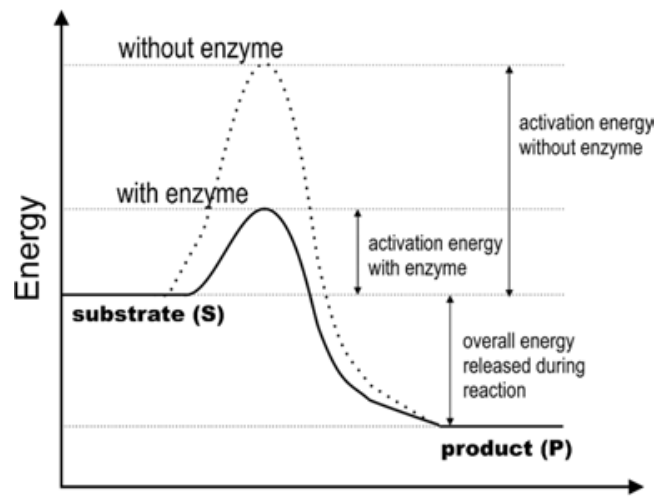

reaction coordinate

Figure 3.2. Gibbs energy change for catalyzed reaction. 


\subsubsection{Equations of enzyme kinetics}

In enzyme kinetics, the initial rate $\left(\mathrm{V}_{0}\right)$ of the enzymatic reaction is the most important parameter, which corresponds to a known fixed substrate concentration (Fig. 3.3). In 1913 Michaelis and Menten proposed a mechanism to explain the dependence of the initial rate of enzyme-catalyzed reactions on concentration, giving rise to what is now known as the Michaelis-Menten equation: ${ }^{25}$

$$
V_{0}=V_{\max } \frac{[S]}{K_{m}+[S]}
$$

where $\mathrm{V}_{\max }$ - the maximum rate of the reaction at saturating substrate concentrations, $[\mathrm{S}]$ - concentration of substrate, $\mathrm{K}_{\mathrm{m}}$ - Michaelis constant, defined as: $^{25}$

$K_{m}=\frac{k_{-1}+k_{2}}{k_{1}}$

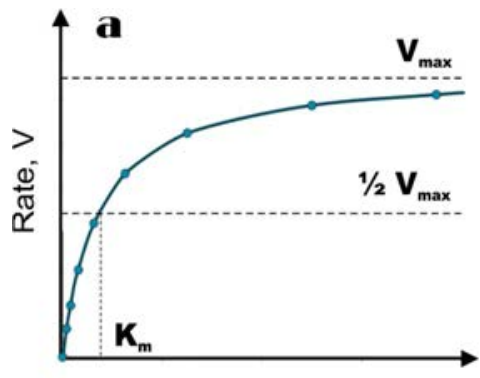

Concentration, [S]

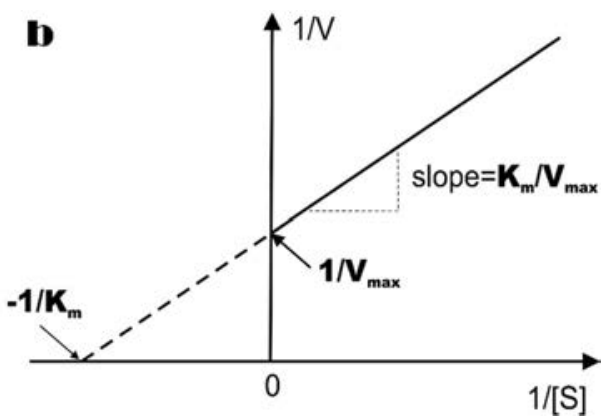

Figure 3.3. Enzymatic kinetics. a. Plot of the initial rate of the enzyme catalyzed reaction $v s$ concentration. b. Lineweaver-Burk plot.

Equation (3.2) is a fundamental equation of enzyme kinetics. When

$$
V_{0}=1 / 2 V_{\max } \Rightarrow K_{m}=[S]
$$

Both parameters, $V_{\max }$ and $\mathrm{K}_{\mathrm{m}}$ can be determined from Fig. 3.3a. However, there is more easy way to determine these parameters from the equation suggested by Lineweaver and Burk: ${ }^{25}$

$\frac{1}{V_{0}}=\frac{K_{m}}{V_{\max }[S]}+\frac{1}{V_{\max }}$

As Fig. $3.3 \mathrm{~b}$ shows, $\mathrm{V}_{\max }$ and $\mathrm{K}_{\mathrm{m}}$ can be obtained from the intercepts and the slope of the straight line. ${ }^{25}$ 
$\mathrm{K}_{\mathrm{m}}$ varies from one enzyme to another and from substrate to substrate for the same enzyme. It depends on enzyme source, temperature, $\mathrm{pH}$, ionic strengths and other reaction conditions. $K_{m}$ is a measure of the affinity between the enzyme and substrate. High $\mathrm{K}_{\mathrm{m}}$ values mean weak affinity and low $\mathrm{K}_{\mathrm{m}}$ values mean strong affinity. ${ }^{24}$ In biosensors, $K_{m}$ values signify the efficiency of an immobilization technique. Comparison between $K_{m}$ values of enzymes in solution and immobilized or between different immobilization techniques allows conclusions about the suitability of a chosen way of immobilization.

$\mathrm{V}_{\max }$ is the maximum rate of an enzymatic reaction, corresponding to a situation where all enzyme molecules have formed the enzyme-substrate complex:

$$
V_{\max }=k_{2}\left[E_{0}\right]
$$

If the initial concentration of the enzyme [ $\left.\mathrm{E}_{0}\right]$ is known, then from values of $\mathrm{V}_{\max }$ we can obtain values of $\mathrm{k}_{2}$ (eq. 3.2, 3.3 and 3.6). $\mathrm{k}_{2}$ is the so called 'turnover number' also known as $\mathrm{k}_{\text {cat }}$ - the catalytic constant. It is the maximum number of molecules of the substrate that can be converted to the product per catalytic site in unit time. Another way to characterize the activity of the enzyme, especially in the case where the purity of the enzyme or the number of active sites per molecule is unknown, is to calculate the activity as units per milligram of protein (specific activity). One unit is defined as the amount of enzyme that produces one micromole of product per minute. ${ }^{25}$

\subsubsection{Factors affecting enzyme activity}

Several factors affect the rate of an enzymatic reaction: temperature, $\mathrm{pH}$, enzyme concentration and presence of inhibitors or activators.

The rate of the enzyme catalyzed reaction, like the rate of most chemical reactions, increases with increasing temperature. Since most enzymes are proteins, they denaturate at temperatures of $40-60{ }^{\circ} \mathrm{C}$. Therefore the dependence of the enzyme activity on temperature has a maximum - the optimum temperature (Fig. 3.4a). ${ }^{26}$ For optimized biosensor performance, it is necessary to know the temperature dependence of the enzyme activity and to work at temperatures close to the optimum.

The $\mathrm{pH}$ dependence of the enzyme activity has a similar shape (Fig. 3.4b). The $\mathrm{pH}$ at the maximum of the curve is called the $\mathrm{pH}$ optimum. Most enzymes have an effective $\mathrm{pH}$ range from 4.0 to $9.0 .^{24}$ To obtain the best performance of a biosensor it is important to work in buffered solutions at the $\mathrm{pH}$ optimum of the enzymatic catalytic activity. 

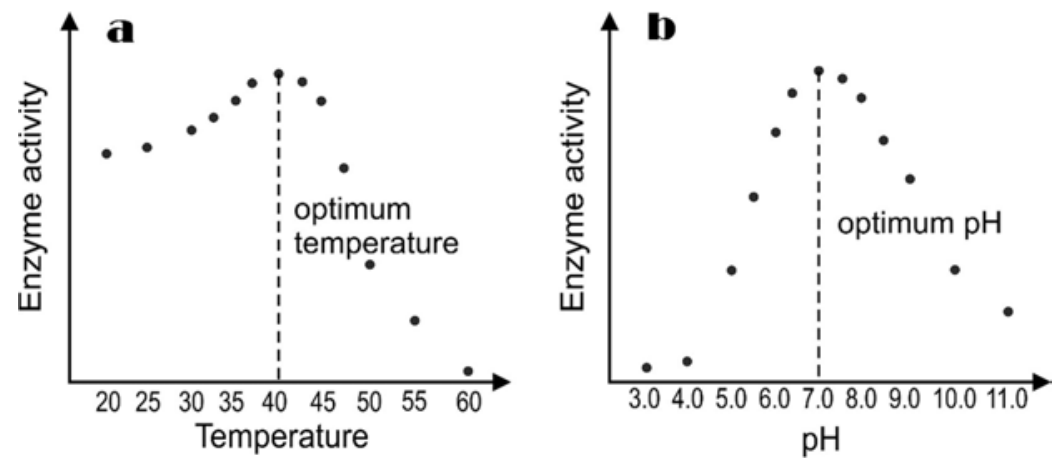

Figure 3.4. Illustration of the dependence of enzyme activity on a. temperature, b. $\mathrm{pH}$.

Inhibitors are compounds decreasing the rate of enzymatic catalytic reactions. Inhibitors can be reversible or irreversible. Michaelis-Menten kinetics is applicable only to reversible inhibition and this type of inhibition is the more common in the area of biosensors.

\subsection{Enzymes used in the work}

For detailed information about enzyme inhibitors, temperature and $\mathrm{pH}$ maxima, the online database http://www.brenda-enzymes.org/ was used. For each enzyme described in the thesis a link to the corresponding page of the database is inserted.

\subsubsection{Glucose oxidase}

Glucose oxidase (GOx, EC 1.1.3.4) is an oxido-reductase with relatively absolute specificity. It catalyzes the oxidation of $\beta$-D-glucose to hydrogen peroxide and D-glucono- $\delta$-lactone which afterwards hydrolyses spontaneously to gluconic acid: $:^{28}$

glucose $+\mathrm{O}_{2} \stackrel{\mathrm{GOx}}{\longrightarrow}$ gluconic acid $+\mathrm{H}_{2} \mathrm{O}_{2}$

GOx extracted from Aspergillus niger is the most commonly used enzyme for biosensors as it is easy to obtain, cheap and can retain its activity at more extreme $\mathrm{pH}$, ionic strength and temperature than many other enzymes, thus allowing it to be used as a standard enzyme for principle studies in the biosensor area. ${ }^{29} \mathrm{~K}_{\mathrm{m}}$ values reported for the enzyme in solution are $33-110 \mathrm{mM} \cdot{ }^{30} \mathrm{GOx}$ from $A$. niger was used for biosensor construction in Papers I, II and III.

GOx from $A$. niger is composed of two subunits; each subunit has one molecule of noncovalently bound coenzyme, flavin adenine dinucleotide (FAD). FAD transfers electrons and protons at the active site of the enzyme. It exists in two redox forms due to the presence of flavin in the structure (Fig. 3.5). ${ }^{31}$ 


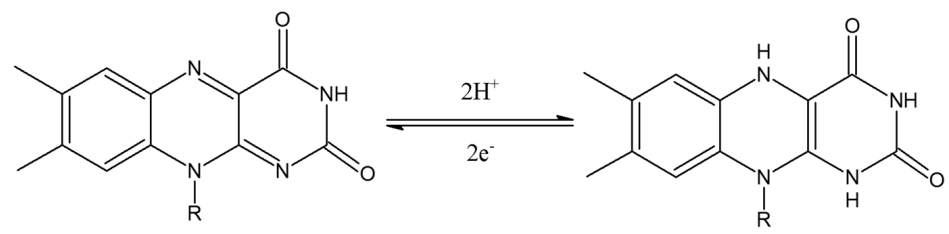

Figure 3.5. Scheme of the flavine redox reaction.

\subsubsection{Lactate oxidase}

Lactate 2-monooxygenase (EC 1.13.13.4) or the synonym: lactate oxidase- LOx (EC 1.1.3.2) is an enzyme that catalyzes the chemical reaction: ${ }^{32}$

L-lactate $+\mathrm{O}_{2} \stackrel{\text { LOx }}{\longrightarrow}$ pyruvate $+\mathrm{H}_{2} \mathrm{O}_{2}$

Lactate is the key metabolite of the anaerobic glycolytic pathway. Lactic acid exists as L-(+) and D-(-) enantiomers. L-(+) -lactate is the normal intermediate in mammalian metabolism, the D-(-) enantiomer is usually produced by microorganisms and algae. ${ }^{33}$

L-lactate determination in blood is required for the diagnosis of various serious symptoms such as shock, metabolic disorders, respiratory insufficiency, and heart failure that can happen in the course of intensive care or during surgery. ${ }^{32}$ Lactate monitoring in blood or sweat is used in sport medicine for control of training programs and athlete efficiency. ${ }^{34}$ In the food industry, the l-lactate level is an indicator of fermentation and is related to the quality of several products such as tomato sauces, fruits, juices, milk, and wine. ${ }^{35,36}$

The structure of the active site of lactate oxidase is not well known yet, as it always has different number of cofactors and water molecules in the structure and it is difficult to stabilize the holoenzyme biomolecule. It is known that the active site contains flavin mononucleotide (FMN). ${ }^{37}$ The redox activity of the active site is provided by flavin (Fig. 3.5).

In order to achieve low detection times at low costs, L-lactate oxidase from Pediococcus species has been used by many laboratories in the construction of lactate sensors. ${ }^{38}$ The enzyme has the advantage of high specificity over other enzymes used for lactate determination. L-lactate oxidase from Pediococcus $s p$. was used in Paper II.

\subsubsection{Cholesterol oxidase}

Cholesterol oxidase (EC 1.1.3.6) (ChOx) is a FAD containing enzyme with absolute specificity. In the presence of oxygen, ChOx catalyzes two reactions; oxidation of cholesterol to cholest-5-en-3-one and subsequently the isomerization to cholest-4-en-3-one: ${ }^{39}$ 
cholesterol $+\mathrm{O}_{2} \stackrel{\mathrm{ChOx}}{\longrightarrow}$ cholest $-4-$ en-3-one $+\mathrm{H}_{2} \mathrm{O}_{2}$

Determination of cholesterol, the cholesterol oxidase substrate, is very important in clinical diagnosis because its level in blood is closely related to human health. A high cholesterol level in the blood increases the risk of clinical disorders such as hypertension, stroke, myocardial infarction, cerebral thrombosis, coronary and peripheral vascular diseases. ${ }^{40}$ The most commonly used ChOx for biosensor construction are isolated from Streptomyces hydroscopicus or Brevibacterium sterolicum. The ChOx from Streptomyces sp. contains noncovalently bound FAD (coenzyme) whereas $\mathrm{ChOx}$ from Brevibacterium sp. has covalently linked FAD (prostetic group). ${ }^{41}$ Despite the higher stability of $\mathrm{ChOx}$ with covalently linked FAD, ChOx from Streptomyces sp. was used in Paper II and IV as it has much higher activity compared to $\mathrm{ChOx}$ from Brevibacterium $s p$. 


\section{4 \\ IMMOBILIZATION TECHNIQUES}

One of the important components that determines biosensor performance is the biocatalytic membrane which accomplishes the conversion of reactant to product. Thus, it is important to know possible ways of creating such membranes on the surface of an electrode, i.e. to immobilize the enzyme, and their drawbacks and advantages, to choose the most suitable one depending on application.

\subsection{Overview of the main immobilization techniques}

Generally, there are 4 main methods for enzyme immobilization (Fig. 4.1): adsorption, entrapment, covalent bonding and cross-linking. ${ }^{42}$ They are briefly described in the following.

\subsubsection{Adsorption}

Adsorption is the simplest and fastest way to construct a biocatalytic layer without significant structural changes of enzyme globules. The enzyme globule can be held on the surface of the electrode via electrostatic interactions, Van der Waals forces or via the formation of covalent bonds. ${ }^{43}$ The main drawback of the adsorption method of immobilization is the low operational stability of the membrane due to enzyme release to the solution. To overcome this drawback layer-by-layer techniques are used. ${ }^{44}$ An enzymatic layer is then covered by an additional protective layer that prevents the enzyme from leaching from the electrode surface. However, such a layer usually decreases the biosensor sensitivity.

\subsubsection{Entrapment}

Entrapment is a method of immobilization that refers to the enclosure of enzyme molecules in a gel or a polymer matrix. The main cons of this method are hindered diffusion of the substrate through the matrix leading to reaction delay and possible loss of bioactivity through pores in the matrix. The matrices commonly used include polyacrylamide, starch gels, nylon, silastic gels, conducting polymers, etc. The advantages of the method are its possibility to include enzyme mediators in the same biocatalytic membrane ${ }^{45}$ and a tunable ionselectivity of the membrane to avoid interference response. ${ }^{46}$ 


\subsubsection{Covalent bonding}

In this method, the bond occurs between a functional group of the biomolecule and the support matrix. During the immobilization, the functional groups of the enzyme that provide catalytic activity should not be involved in the reaction. It requires mild conditions under which reactions are performed. Covalent immobilization of biomolecules on the electrode surface provides high stability of the biocatalytic layer. ${ }^{47}$ The main disadvantage of the method is a high possibility to harm the catalytic activity of an enzyme globule during immobilization. ${ }^{48}$

\subsubsection{Cross-linking}

In this method, biomolecules are chemically bonded to each other or to a crosslinking agent. The method is attractive due to its simplicity and strong stabilization of the adsorbed material. The main drawback is a possibility to lose enzymatic activity due to deformation of the enzyme active site. Glutaraldehyde is the mostly used bifunctional agent for cross-linking. The agents can also interfere with the enzyme activity, especially at higher concentrations. ${ }^{49}$
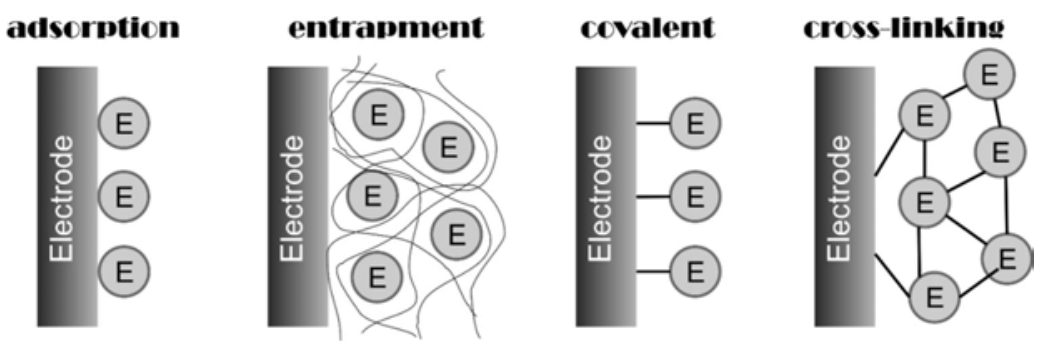

Figure 4.1. Schematic representation of the main different methods of enzyme immobilization.

\subsection{Sol-gel immobilization}

In the research presented in this thesis I used entrapment of biomolecules in a sol-gel matrix as the method for enzyme immobilization. The process is briefly described in the following.

\subsubsection{Sol-gel process}

The sol-gel process is a low temperature method for trapping enzymes in inorganic glasses. The application of the sol-gel process for enzymes was first demonstrated in 1990 by Braun and co-workers and has developed apace since that time. ${ }^{50}$ 
During the sol-gel process alkoxide monomers undergo hydrolysis to form silanols. Condensation of silanols with subsequent aging and drying processes under ambient atmospheres leads to the formation of porous sol-gel matrices. The chemistry of such a process is presented below: ${ }^{51}$

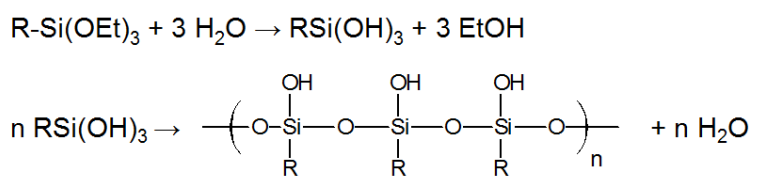

The most widely used monomers for the sol-gel process are tetramethoxysilane (TMOS) and tetraethoxysilane (TEOS). However, the introduction of various organic functional groups into the monomers leads to organically modified solgel glasses, or ormosils. Ormosils have several advantages compared to inorganic sol-gels: ${ }^{51}$

- Possibility of specific binding of a biomolecule to the matrix;

- Possibility to incorporate a mediator to the same matrix as the enzyme;

- Possibility to tune the wettability of the matrix, controlling the ratio of hydrophilic to hydrophobic monomers, ${ }^{52,53}$

- Possibility to control thickness and porosity of the biocatalytic layer. ${ }^{54,55}$

There are four different approaches for enzyme immobilization in a sol-gel matrix (Fig. 4.2): ${ }^{51}$

- Enzyme entrapment in the matrix; ${ }^{56}$

- Enzyme attachment on the surface of an ormosil ${ }^{57}$

- Enzyme immobilization in a sandwich configuration, $;^{58}$

- Enzyme immobilization in a bilayer configuration. ${ }^{59}$
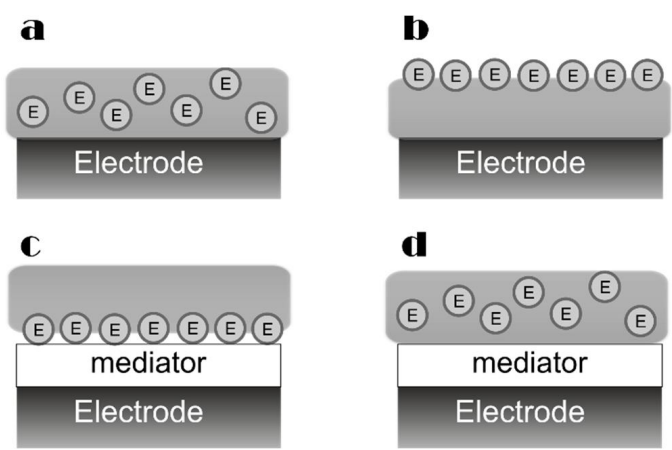

Figure 4.2. Scheme of different approaches of enzyme immobilization in sol-gel. a. Entrapment. b. Enzyme attachment on the surface of an ormosil. c. Sandwich configuration. d. Bilayer configuration (reproduced with modifications). ${ }^{51}$ 
The choice of immobilization approach depends on the convenience, stability and sensitivity required by the biosensor. In Papers I-III and partially IV enzyme entrapment in the sol-gel matrix together with a mediator was used. In Paper IV the bilayer configuration was also used, $\mathrm{ChOx}$ in a sol-gel matrix was immobilized on top of an electrode covered by Prussian blue (ferric ferricyanide).

In all papers included in the thesis, we used 3-aminopropyl-triethoxysilane (APTEOS) as a monomer for formation of the gel matrix (Fig. 4.3). In Paper I two additional siloxanes were tested as a matrix for enzyme immobilization, vinyl- and phenyl- triethoxysilanes, however biosensors based on APTEOS have shown better operational stability. The organic structure in the APTEOS provides a strong cage for enzyme molecules and allows to overcome enzyme leaching problems. The presence of amino groups in the ormosil creates a hydrophilic microenvironment beneficial for biomolecules. ${ }^{60}$
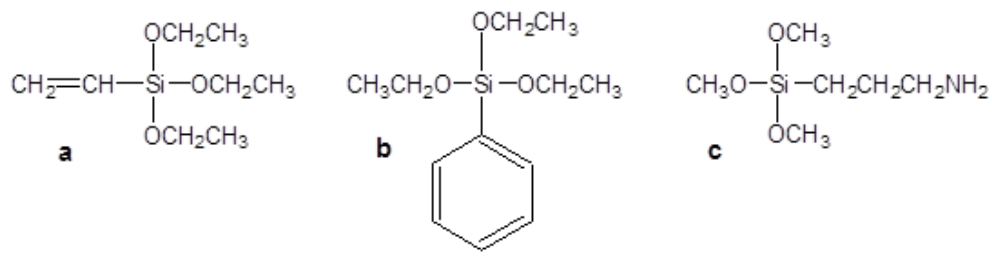

Figure 4.3. Structural formulas of a. vinyl-, b. phenyl, c. 3-aminopropiyl-triethoxysilane.

\subsubsection{Immobilization from organic solvent}

Preparation of uniform gel membranes requires media with a high content of organic solvent. As a uniform membrane can be obtained only from a diluted solution of monomers (1-3\%) and for hydrolysis of one molecule of monomer 3 to 4 molecules of water are needed, the concentration of water in the solution should not exceed $15 \%$. Higher concentration of water leads to spontaneous hydrolysis and condensation and therefore to a heterogeneous membrane. ${ }^{61}$ However, when using high content of organic solvent for the immobilization, problems of enzyme stability arise.

In the research presented in this thesis, we used the concept of enzyme immobilization from water-organic mixtures with a high content of organic solvent, based on the knowledge that enzymes can retain their activity after being exposed to such media. ${ }^{62,63}$ It has been shown previously that the dependence of the enzyme catalytic activity in a water-organic mixture on the organic solvent concentration has three regions. ${ }^{64}$ There is no significant decrease in enzyme activity at low content of organic solvent (0-20\%). At concentrations higher than a critical value ('threshold value') ${ }^{65}$ the enzyme undergoes conformational changes and completely loses its activity. In concentrated organic solutions with a water content less than $10-15 \%$ the enzyme activity reappear. The reasons of 
the phenomena are still not clear. One suggestion is that the enzyme becomes insoluble in such media and that the presence of colloid particles prevents biomolecules from inactivation by the organic solvent. ${ }^{62}$

Fig. 4.4 represents our investigation of enzyme (GOx) activity in waterisopropanol mixtures that we used for sol-gel immobilization of biomolecules in all research presented in the thesis. As can be seen the maximum of the remaining activity occurs at $15 \%$ of water, which coincides with the waterisopropanol azeotrope. This mixture was used for immobilization of biomolecules in our work.

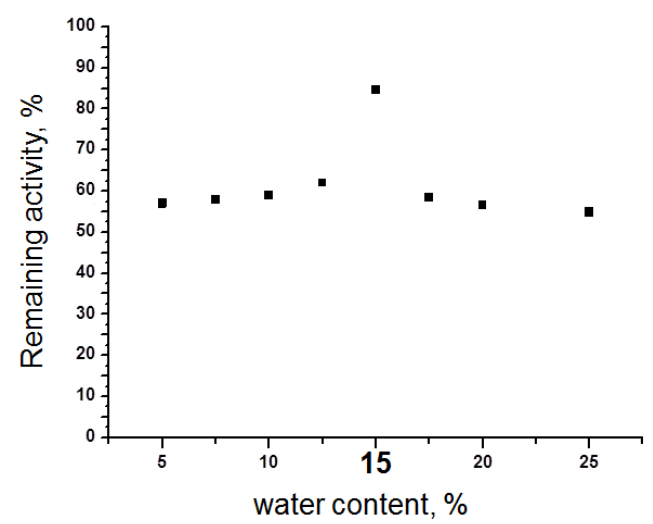

Figure 4.4. Remaining activity of glucose oxidase after $10 \mathrm{~min}$ of exposure to waterisopropanol mixtures. 



\section{5}

\section{REAGENTLESS BIOSENSOR ARCHITECTURES}

The reagentless biosensor is the most widely used architecture for a variety of applications. The unique feature of a reagentless biosensor is that all components needed for the electroanalytical reaction are immobilized on the electrode surface..$^{20}$ In this chapter two examples of reagentless electrochemical biosensor configurations, mediated biosensors and self-powered biosensors, will be discussed.

\subsection{Mediated biosensors}

Mediated enzyme biosensors (or 'second-generation' biosensors) nowadays find broad applications in different fields of analysis. Despite several attempts to use quiones, azines and metal complexes ${ }^{66,67}$ as mediators in the 1970 s, wide application of mediated biosensors started from the discovery of the possibility to use the ferricinium ion (oxidized ferrocene) as a mediator for GOx in $1984 .{ }^{68}$

\subsubsection{Mediator}

A mediator is a redox active molecule that can act as an artificial enzyme substrate in an enzymatic redox reaction and shuttle electrons between the active site of the enzyme and an electrode. In a catalytic reaction the mediator first reacts with the enzyme active site and then participates in rapid electron transfer with the electrode that can be observed as a typical response in a cyclic voltammogram (CV) (Fig. 5.1). Similar CV responses were observed for PTZ in a gel membrane in Papers I and III as well as for PTZ and GOx in acetonitrile in Paper II. Mediated catalytic reactions can, in the case of GOx, be described as follows: ${ }^{69}$

$$
\begin{aligned}
& \text { glucose }+\mathrm{FAD}+\mathrm{H}_{2} \mathrm{O} \rightarrow \text { gluconic acid }+\mathrm{FADH}_{2} \\
& \text { FADH }{ }_{2}+M_{o x} \stackrel{k_{s}}{\longrightarrow} F A D+M_{r e d}+2 H^{+} \\
& \text {At electrode }: M_{\text {red }} \rightarrow M_{o x}
\end{aligned}
$$


The CV shown in Fig. 5.1 can be used for determination of the catalytic rate constant of an enzymatic reaction $\left(\mathrm{k}_{\mathrm{s}}\right)$. According to the Nicholson-Shain equation a pseudo-first-order rate constant, $\mathrm{k}_{\mathrm{f}}$, can be written as: ${ }^{70}$

$$
k_{f}=k_{s}[G O x]=a\left(\frac{i_{c}}{i_{p}}\right)^{2}
$$

where $\mathrm{a}=\mathrm{nFv} / \mathrm{RT}, \mathrm{v}$ is the scan rate, $\mathrm{n}-$ the number of electrons transferred, $\mathrm{i}_{\mathrm{c}}$ and $i_{p}$ are the catalytic and peak currents of the mediator measured from $\mathrm{CV} b$ and a in Fig. 5.1, respectively, and all other symbols have their usual meaning (see section 2.1). Plots of $\left(i_{c} / i_{p}\right)^{2}=k_{f} / a$ vs $1 / v$ for different concentrations of enzyme allows determination of $\mathrm{k}_{\mathrm{f}}$. Finally, a plot of $\mathrm{k}_{\mathrm{f}} v s$ concentration of the enzyme is used to calculate $\mathrm{k}_{\mathrm{s}}$.

The current produced by oxidation of the reduced form of the mediator $\left(\mathrm{M}_{\mathrm{red}}\right)$, generated as a result of the enzymatic reaction, is measured amperometrically at a potential corresponding to steady-state current on the cyclic voltammogram (Fig. 5.1).

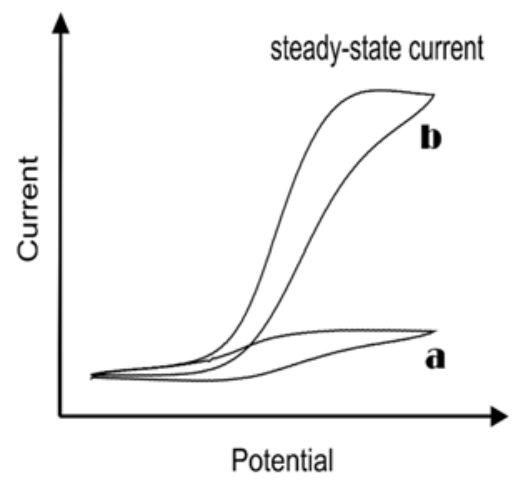

Figure 5.1. Typical cyclic voltammogram of a mediator. a - No enzymatic reaction occurs. $b$ - Mediator response as a result of enzymatic reaction.

The mediator should fulfill certain requirements: the redox potential of the mediator should be small enough to avoid interfering electrochemical reactions, both the oxidized and reduced forms of the mediator should be stable enough and the second-order rate constant for the reaction between the mediator and the enzyme should be high enough to minimize competition with oxygen. ${ }^{71}$ Mediated biosensors with appropriately selected mediators possess several significant advantages: the catalytic reaction becomes independent of the presence of natural electron acceptors or donors (for example oxygen), the influence of possible interfering compounds can be reduced, the $\mathrm{pH}$ dependence of the sensor response can be better controlled and the sensitivity and current response of the biosensor can be increased. ${ }^{20}$ 


\subsubsection{Commonly used mediated systems}

Ferrocene and its derivatives, ferri/ferrocyanide complexes of transition metals such as osmium and ruthenium as well as redox organic dyes (mainly azines) are widely used redox mediators for oxidases. Ferri/ferrocyanide is one of the most commonly used and most efficient soluble inorganic mediators. ${ }^{72-74}$ However due to its small size and high solubility, it easily diffuses away from the electrode surface into the bulk solution, which reduces the long-term operational stability and hampers its application in both continuous laboratory analysers and implantable probes. The less soluble ferrocene derivatives provide a partial solution to this problem and have achieved considerable success in commercial home-use devices, but the ferrocinium ion is still soluble. ${ }^{75}$ Tertrathiafulvalene has been proposed as one alternative to ferrocene derivatives as an insoluble mediator for amperometric biosensors. ${ }^{76,77,78}$ In spite of their high efficiency in mediating the electron transfer of oxidases, osmium and ruthenium complexes ${ }^{79,80}$ have essential drawbacks due to their high toxicity.

\subsubsection{Azines as mediators for oxidases}

Azines is one of the widely used mediators for oxidases. Azines is a class of organic compounds that can be considered as derivatives of phenazine (Fig. 5.2).

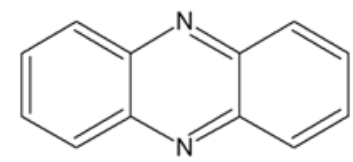

Figure 5.2. Chemical formula of phenazine.

Azines are aromatic structures with pronounced redox properties (Fig. 5.3) ${ }^{81}$ The main advantage of azines compared to ferrocene and some other commonly used mediators is that at open circuit potential they occur in oxidized form, i.e. in the form that is ready to react with the active site of an enzyme. Historically, methylene blue, one of the representatives of azines, was the first redox mediator of GOx. ${ }^{82}$ Several azines such as methylene green ${ }^{83}$, methylene blue ${ }^{84}$, meldola blue $^{85}$, celestine blue ${ }^{86}$, phenazine ${ }^{87,88}$, thionine ${ }^{89}$, azure $\mathrm{B}^{90}$, toluidine blue ${ }^{91}$ can be used as electron transfer mediators for oxidases when immobilised on the electrode surface. The main drawback of organic dye-based biosensors is the leakage of catalytic material from the electrode surface. Thus, many studies have been performed with the aim to improve the operational stability of such devices.

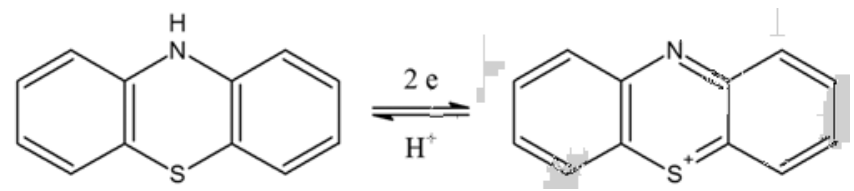

Figure 5.3. Redox properties of azines on the example of phenothiazine. 
In Papers I and II we have evaluated the possibility to eliminate mediator leakage by using a new, water-insoluble mediator for oxidases - unsubstituted phenothiazine (PTZ).

\subsubsection{Enzyme and mediator co-immobilization}

The main drawbacks of mediated biosensors were discussed above. Due to these drawbacks, the development of reagentless biosensors with enzyme and mediator co-immobilized on the electrode surface has become essential over the last 15 years. ${ }^{20}$ There are several techniques available for enzyme immobilization as described previously (chapter 4). However, the immobilization matrix for a reagentless biosensor should provide possibilities for immobilization not only biomolecules, but in addition, suitable binding sites for mediators.

Effective retention of the mediator in the catalytic membrane can be achieved by covalent bonding between the mediator groups and the matrix-formed polymer or gel used for enzyme entrapment. The best known examples, which have also had a remarkable commercial success in home blood glucose tests, are biosensors with the membrane formed by poly(vinylpyridine) $)^{92}$ and poly(vinylimidazole $)^{79,93}$ with Os complexes as a mediator.

Nevertheless, simplification of the biosensors, required for their mass production, dictates a search for methods of mediator immobilization without covalent linking. It was shown in the 1980s that the mediator can be efficiently trapped in polyelectrolyte membranes ${ }^{94}$ due to electrostatic interactions. Since then several works have been published on enzyme and mediator co-immobilization in polymer matrixes without covalent mediator linking. ${ }^{95}$

We have used the sol-gel method for enzyme and mediator co-immobilization in Papers I-IV. Advantages of the method for enzyme immobilization were discussed previously (chapter 4). The method allows to immobilize the mediator in the matrix without covalent linking. Retention of the mediator in the gel is most likely provided by weak hydrogen bonds between sulfur in the aromatic ring of the mediator and the aminogroups of APTEOS and by the hydrophobic nature of the mediator. The assumption about the existence of hydrogen bonds is based on results obtained in Paper I showing higher operational stability of a biosensor using APTEOS as the immobilization matrix compared to two other siloxanes without aminogroups.

\subsection{Self-powered biosensors}

Self-powered biosensors can be considered as a striking example of the continued development of redox-enzyme electrodes. ${ }^{20} \mathrm{My}$ work presented in the thesis confirms this statement. As a result of the development of the enzyme 
electrodes presented in Papers I and II we have constructed a biosensor with self-powered configuration described in Paper IV.

A self-powered biosensor is a type of enzymatic biofuel cell (BFC) with power output, either open circuit potential (OCP) or a current proportional to the fuel concentration. ${ }^{96}$ The concept of a BFC as an analytical device was introduced in 2001 by Willner's group. ${ }^{97}$

\subsubsection{Enzymatic fuel cells}

BFCs based on enzymes have been known since 1964. ${ }^{98}$ However, they received revived attention last decade as a new energy conversion technology when Willner and co-workers published work on a membraneless enzymatic BFC. ${ }^{99}$

BFCs transform the energy of a biological catalytic reaction into electricity by oxidizing a fuel at the anode and reducing an oxidant at the cathode. ${ }^{100}$ They are categorized according to the biological catalyst used for the fuel oxidation. Microbial BFCs use living cells or organelles as catalysts. ${ }^{96}$ In enzymatic BFCs enzymes are used as a catalyst for fuel oxidation. To understand the working principle of an enzymatic BFC one can consider it as a combination of two enzyme electrodes (Fig. 5.4). These two electrodes can be mediated biosensors as presented in Fig. 5.4 as well as any other possible combination of enzyme biosensors of different generations. Cells in which the reaction at only one electrode is catalyzed by an enzyme and the other is a noble metal catalyst are also considered as enzymatic BFCs. ${ }^{101}$

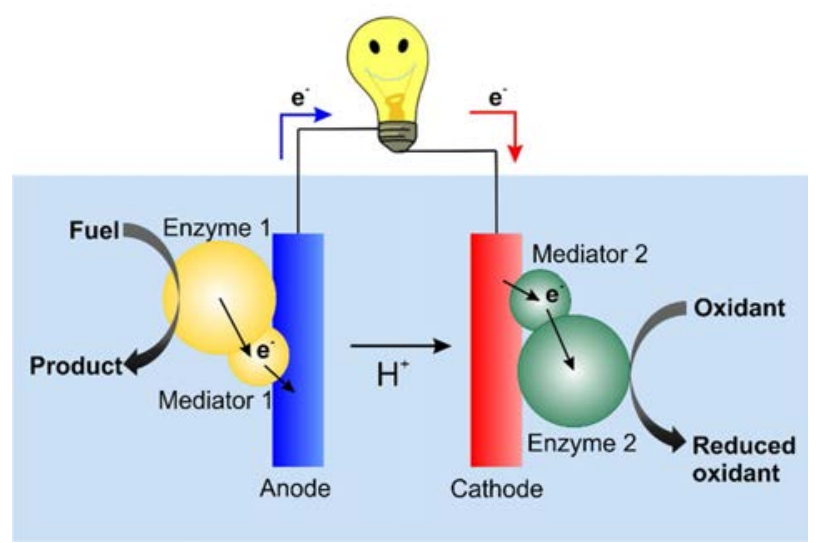

Figure 5.4. Scheme of the example of the enzymatic biofuel cell.

\subsubsection{Power, cell voltage and current}

The power output is one of the main characteristics of fuel cell performance. It depends on the current detected at different cell voltages (Fig. 5.5). At one extreme of this dependence is the so called the open circuit potential (OCP), 
which is a measure of the maximum voltage provided by a fuel cell. It is determined as the difference between the formal redox potentials of the fuel/product and oxidant/reduced oxidant couples. At the other extreme we have the short circuit current. It occurs when the anode and cathode are electrically connected (i.e. no voltage applied). Useful power appears at current and voltage values between OCP and short circuit potential. ${ }^{101}$

Cell voltages depend on the fuel and oxidant, the rate of electron transfer, the current flowing, resistance within the cell and mass transport processes. ${ }^{100}$

The value of the current is determined by the slowest electrocatalytic reaction (anodic or cathodic). The maximum electrocatalytic current that can be achieved at the anode or cathode depends on the density of catalytic active sites and the rate of catalysis per active site. ${ }^{101}$

Power, cell voltage and current were determined for the self-powered biosensor described in Paper IV.
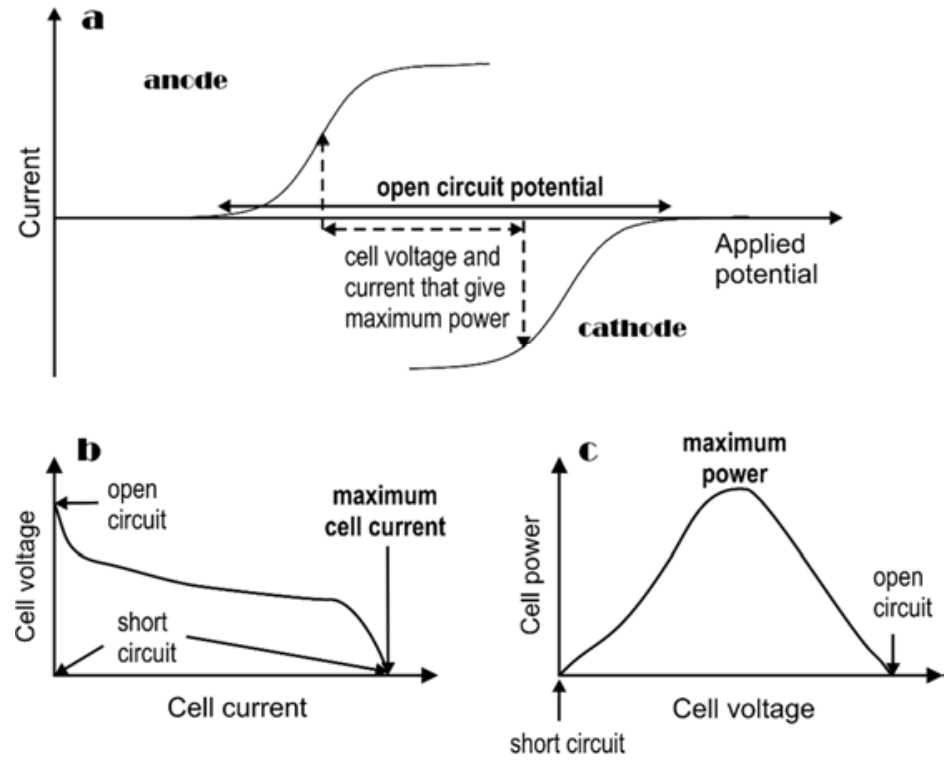

Figure 5.5. Illustration of factors that determine fuel cell performance. a. Open circuit potential. b. Maximum cell current. c. Maximum power. (reproduced with modifications). ${ }^{101}$

\subsubsection{Important examples of self-powered biosensors}

As was mentioned above the concept of using a membrane-free BFC to measure analyte concentrations was first described by Willner and co-workers in $2001 .{ }^{97}$ 
They have designed two different self-powered biosensors. The first system consisted of two enzyme-functionalized gold electrodes acting as anode and cathode. On the anode, GOx was immobilized via covalent bonding with a polymer monolayer on the surface of the electrode. The cathode has cytochrome c (Cyt c) attached to the electrode and cytochrome c oxidase crosslinked to the Cyt c for $\mathrm{O}_{2}$ reduction. This system used glucose as fuel and the OCP of the system was proportional to the fuel concentration. The second system has the same biocathode and a bioanode with immobilized lactate dehydrogenase. This system used lactate as fuel in a similar way. The main advantage of such self-powered biosensing devices is that they can operate without any power input, producing power and thus making it attractive for potential use in implantable devices ${ }^{102}$ and in inexpensive screening devices based on printed electronics. ${ }^{18}$ However, the use of two enzymes increase the cost of the device. Also, enzymes might have different optimum conditions. These issues were overcome in Paper IV by using a special configuration of the BFC employing the same biocatalyst - ChOx for both anode and cathode.

In 2011, the first logic gate made of a self-powered enzymatic biosensor was reported by Dong's group. ${ }^{103}$ The system consisted of a GOx based anode and a bilirubin oxidase based cathode. Both enzymes were co-immobilized with mediators in a biopolymer, chitosan. The ON state (high power output) for the system was achieved in air-saturated solutions, too high or too low levels of $\mathrm{O}_{2}$ led to an OFF state (low power output). Such $\mathrm{O}_{2}$ controlled switchable BFCs could be used as implantable diagnostic systems which monitor the $\mathrm{O}_{2}$ content in body fluids and make a logic decision whether the level of dissolved $\mathrm{O}_{2}$ in the body fluid is within acceptable limits or not. The main disadvantage of most reported logic self-powered biosensors is that they are activated by signals not relevant for in vivo applications (due to the nature of the signal or to nonphysiological concentrations). ${ }^{102}$

Other important self-powered biosensors are those based on the inhibition effect. Enzyme inhibitors can be detected through their influence on the power output of BFCs. In 2010 Dong's group developed the first self-powered cyanide biosensor. ${ }^{104}$ The BFC consisted of a glucose dehydrogenase (GDH) based bioanode and a laccase based biocathode. Laccase catalyzes the reduction of $\mathrm{O}_{2}$ to water and has copper in its active site. Cyanide affects the active site of laccase and inhibit $\mathrm{O}_{2}$ consumption but does not affect the GDH activity. The decrease of $\mathrm{O}_{2}$ reduction on the biocathode resulted in a decrease of the power output which is then a measure of the cyanide concentration.

Another possible way of using the reversible inhibition effect in self-powered biosensors is measuring the recovery of the power output of the BFC induced by molecules that can decouple the inhibition effect and thus detect these molecules. Minteer's group described the first enzymatic BFC using this principle in 
2011. ${ }^{105}$ The BFC consisted of a GOx-based bioanode and a Pt cathode and was used for sensing of ethylenediaminetetraacetic acid (EDTA). The GOx based anode was inhibited before sensing by using $\mathrm{Cu}^{2+}$ that binds to the active site of the enzyme. EDTA was shown to reverse the binding of $\mathrm{Cu}^{2+}$ to the active site and recover the power output of the BFC. Since different molecules can inhibit enzymes or decouple the inhibition effect, the main disadvantage of self-powered biosensors based on the inhibition effect is their selectivity.

The new developments in self-powered biosensing utilizing inhibition, uncoupling and logic sensing have led to an increase in the number of analytes that can be detected by self-powered sensors and to lower the analyte concentrations that can be detected. 


\section{6 \\ EXPERIMENTAL METHODS}

\subsection{Electrochemical techniques}

For all electrochemical techniques the same experimental set-up, described below, was used.

\subsubsection{Experimental set-up}

\section{Electrochemical cell}

For electrochemical measurements an electrochemical cell is required (Fig. 6.1). In the simplest experiments, the cell has a two- or a three-electrode configuration. In my work, a two-electrode configuration was used for the self-powered biosensor characterization in Paper IV, as it is the standard configuration for BFCs (see section 5.2). For all other electrochemical measurements, a threeelectrode cell was used. A potentiostat was used to control the applied potential and record the current on the working electrode.

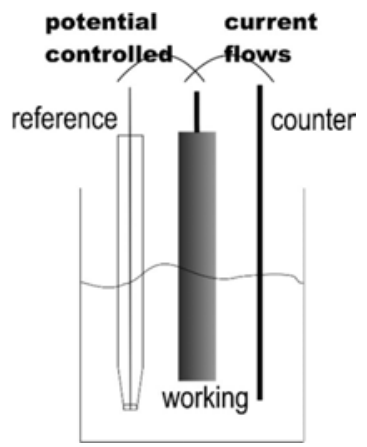

Figure 6.1. Scheme of the electrochemical cell.

\section{Working electrodes}

All working electrodes used in the work were made of carbon (Fig. 6.2). Carbon might be the most widely used material in biosensor applications. ${ }^{106}$. Despite extensive past investigations of carbon materials for electrochemistry, recent years have brought fundamental innovations that add significantly to the utility of this material for biosensors. Screen-printed carbon structures (Papers I-IV), carbon microelectrodes (Paper III) and carbon electrodes with large surface area 
(Paper IV) offer distinct properties compared with the graphitic carbon electrodes used in the early 1990s and also enable development of novel biosensors.

a

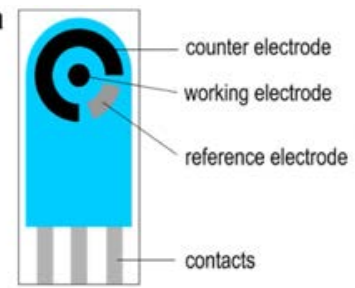

C

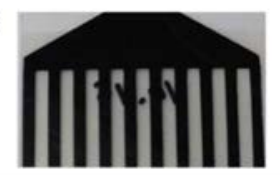

b

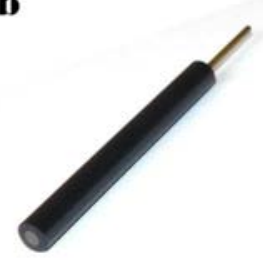

(1)

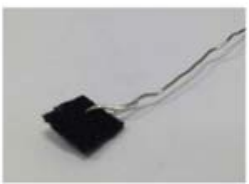

Figure 6.2. Working electrodes used in the work. a. Scheme of the screen-printed threeelectrode system. b. Photo of glassy carbon electrode. c. Photo of screen-printed graphite microband array. d. Photo of carbon cloth electrode.

\subsubsection{Potential sweep techniques}

Potential sweep techniques are based on scanning a chosen region of potential and measuring the resulting current due to the electrode processes.

\section{Linear-sweep voltammetry}

If we perform linear-sweep voltammetry (LSV) for investigation of the reaction (2.1) and assume that this reaction is reversible (an assumption used in the reactions investigated in this work), the potential of the working electrode should be swept from value $E_{1}$ at which $O$ cannot undergo reduction to a potential $E_{2}$ where the reaction occurs rapidly. Fig. 6.3 shows the scheme of the potential sweeping and the corresponding current response.

The current response has a peak-shaped form. The current starts to rise when the potential reaches the value at which electrode reaction can occur. Due to fast electrode reaction at potentials higher than this 'initial potential' and slow diffusion of electroactive species, the current finally decreases as a result of depletion (diffusion limitation). ${ }^{107}$ 

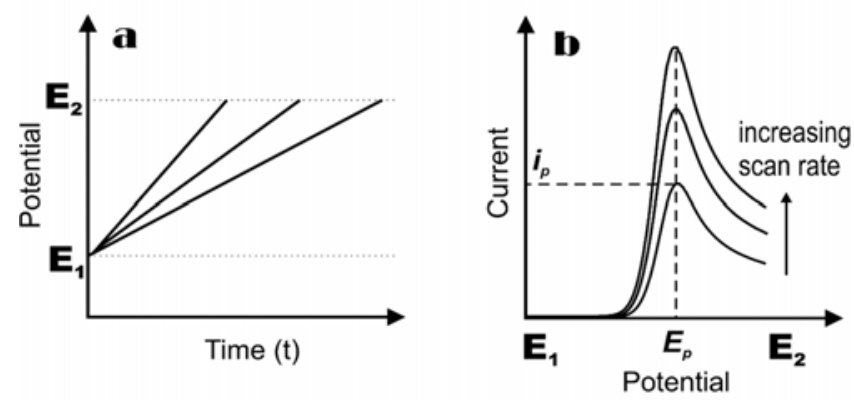

Figure 6.3. Linear sweep voltammetry. a. The potential sweep. b. Corresponding current response for the reaction (2.1).

The peak current in LSV can be described by the Randles-Sevcik equation: ${ }^{107}$

$I_{p}=0.4663 n F A C\left(\frac{n F v D}{R T}\right)^{1 / 2}$

where $\mathrm{n}$-number of electrons transferred, $\mathrm{A}$-electrode surface area, Ddiffusion coefficient of the electroactive species, $\mathrm{C}$-concentration of the electroactive species in solution far from the electrode surface, $\mathrm{v}$ - scan rate, and all other symbols have their usual meaning (see section 2.1).

LSV at low scan rates (polarization curve) was used for determination of the OCP and the rate-determining counterpart of the self-powered biosensor in Paper IV.

\section{Cyclic voltammetry}

Cyclic voltammetry (CV) can be described as an extension of LSV. When the potential reaches the value $\mathrm{E}_{2}$, the direction of the sweep is reversed and the potential is scanned back to the value $E_{1}$. Fig. 6.4 represents the scheme of the potential sweeping and the resulting cyclic voltammogram of the process.
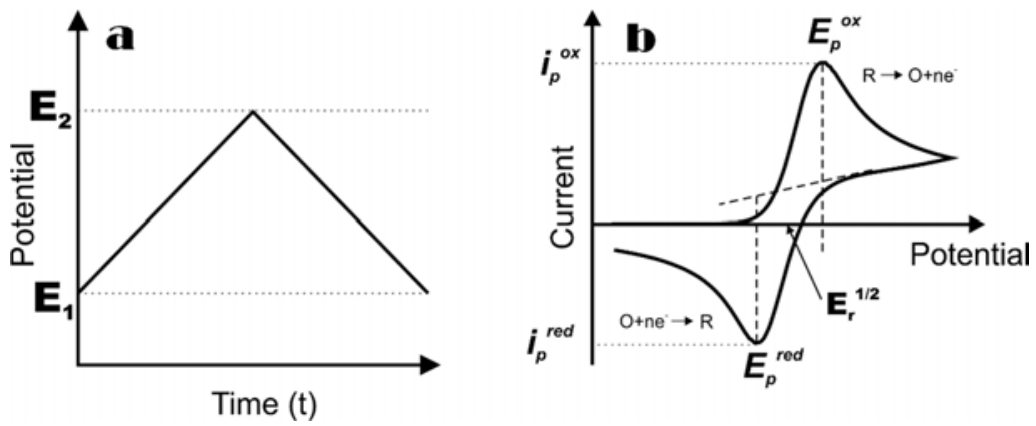

Figure 6.4. Cyclic voltammetry. a. The potential sweep. b. Corresponding cyclic voltammogram for the reaction (2.1). 
For a reversible electrode reaction, the peak current in $\mathrm{CV}$ can be described by the Randles-Sevcik equation as for LSV, eq. (6.1). The peak currents of the forward and reverse scans have the same magnitude and the peak to peak separation is described by: ${ }^{107}$

$$
E_{p}{ }^{o x}-E_{p}{ }^{r e d}=2.218 \frac{R T}{n F}
$$

$E_{1 / 2}^{r}$, the half-wave potential (Fig. 6.4) - potential in the middle of the peaks, is an important characteristic as it is related to the formal potential of the reaction $\left(\mathrm{E}^{0}\right.$, see section 2.1.2): ${ }^{7}$

$$
E_{1 / 2}^{r}=E^{0^{\prime}}+\frac{R T}{n F} \ln \left(\frac{D_{R}}{D_{O}}\right)^{s}
$$

where $D_{R}$ and $D_{O}$ - diffusion coefficients of the reduced and oxidized forms, respectively; $s=1 / 2$ for stationary electrodes in stationary solutions, $s=1$ for microelectrodes, $s=2 / 3$ for hydrodynamic electrodes (rotating disk electrode). ${ }^{7}$

$\mathrm{E}_{1 / 2}^{\mathrm{r}}$ for the $\mathrm{CV}$ can be calculated from the potentials of the peaks:

$$
E^{r}{ }_{1 / 2}=\frac{E_{p}^{o x}+E_{p}^{r e d}}{2}
$$

CV was used for determination of the PTZ diffusion coefficient in the siloxane gel from the Randles-Sevcik equation and for investigation of the catalytic effect in Paper I. In Paper II the diffusion coefficient of PTZ in acetonitrile and the catalytic constant for the enzymatic reaction was calculated from data of $\mathrm{CV}$ measurements using the Nicholson-Shain equation ${ }^{70}$ (see section 5.1.1). Also voltammetry was used to assess enzyme stability in a water-acetonitrile solution. In Paper III CV measurements were employed for characterization of screenprinted microband arrays and comparison of their characteristics with screenprinted macroelectrodes.

\subsubsection{Potential step chronoamperometry}

Being a complementery approach to potential sweeping techniques, chronoamperometry measurements, where the current is sampled while the potential of the working electrode is instantly stepped between the values $E_{1}$ and $\mathrm{E}_{2}$ for reaction (2.1) (Fig. 6.5a), offer time-resolved voltammetric data.

Immediately after the step a large current is detected which falls with time due to depletion of the electroactive species near the electrode surface (Fig. 6.5b). The Cottrell equation describes the dependence of the current response on time for electrodes with planar diffusion: ${ }^{107}$ 
$|i|=\frac{n F A D_{O}{ }^{1 / 2}[O]}{\pi^{1 / 2} t^{1 / 2}}$

where $[\mathrm{O}]$ - bulk concentration of $\mathrm{O}$ (eq. (2.1)).
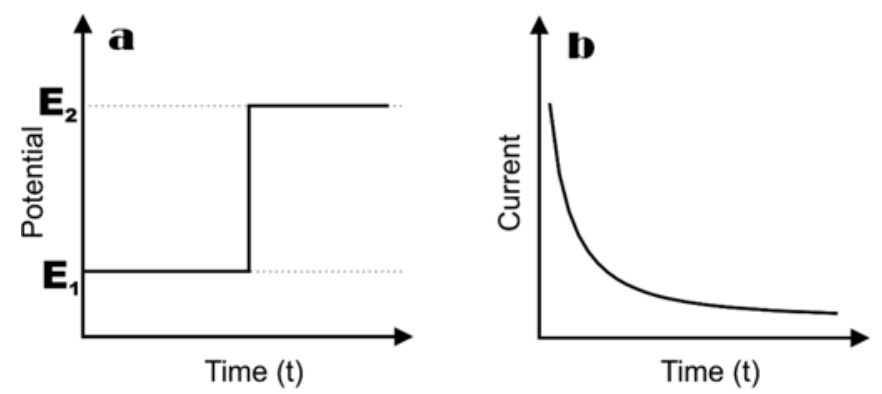

Figure 6.5. Chronoamperometry. a. The variation of applied potential. b. Current response.

Double step chronoamperometry is a commonly used multistep technique. In this case, the working electrode is first held at an initial potential. Then it is stepped to a specific potential for a period of time. After the first step, the potential is stepped back to the initial potential.

Chronoamperometry was used in Papers II and IV for characterization of the analytical performances of $\mathrm{GOx}, \mathrm{LOx}, \mathrm{ChOx}$ based biosensors and the counterparts of the self-powered biosensor, respectively and for blood plasma measurements in Paper IV. Double potential step chronoamperometry was employed for the investigation of the electron transfer process between the enzyme and PTZ in Paper I. In Paper III the width of the microband electrodes was calculated from chronoamperometry measurements using a modified Cottrell equation for microband electrodes derived by Aoki and co-workers. ${ }^{108}$

\subsubsection{Differential pulse voltammetry}

In differential pulse voltammetry (DPV) the potential applied to the working electrode has a form as shown in Fig. 6.6a. DPV measures the difference between the currents sampled before and at the end of a pulse. The current difference plotted against the sweeping potential yields to differential voltammogram featured with a peak-shaped response of the electrode reaction (Fig. 6.6b). The potential of the peak is related to the half-wave potential (see LSV): ${ }^{7}$

$$
E_{p}=E^{r} 1 / 2-\frac{\Delta E}{2}
$$

where $\Delta \mathrm{E}$ is the pulse amplitude. The peak current $\left(\mathrm{I}_{\mathrm{p}}\right)$ can be described as follows: 
$I_{p}=\frac{n F A D^{1 / 2} C}{\left(\pi t_{m}\right)}\left(\frac{1-\sigma}{1+\sigma}\right)$

$\sigma=\exp \left(\frac{n F}{R T} \frac{\Delta E}{2}\right)$

where $t_{m}$ is the sampling time, $\mathrm{C}$ - concentration of the electroactive species.

The dependence of the peak current on the concentration can be used for characterization of the analytical performance of an electrode. DPV is more sensitive than LSV and CV in terms of detection of electroactive species as it allows to eliminate contributions of the capacitive current due to measurements of current difference.
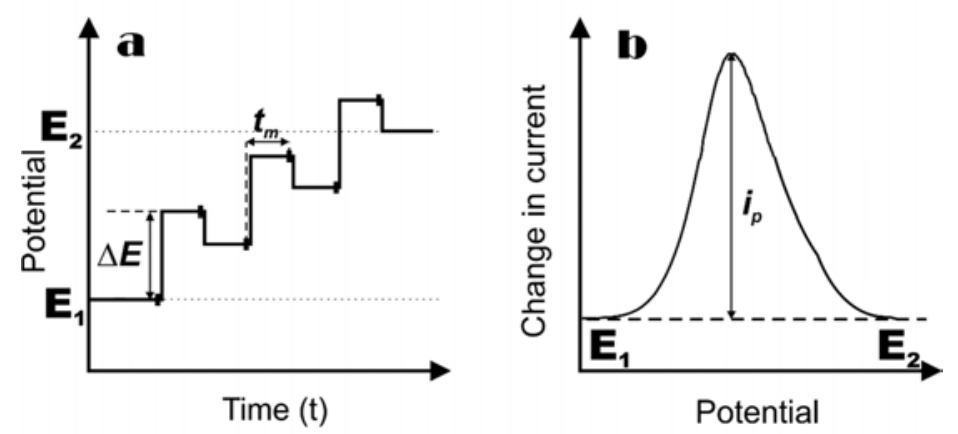

Figure 6.6. Differential pulse voltammetry. a. The variation of the applied potential. $b$. Current response.

DPV was used in Paper II for detection of ascorbic acid on screen-printed microband arrays of different geometry.

\subsubsection{Measurements on hydrodynamic electrodes}

Hydrodynamic electrodes are electrodes with the mass transport process dominated by convection. There are two common types, the rotating disk electrode and the wall-jet electrode.

\section{Rotating disk electrode}

The rotating disk electrode (RDE) used in this work is a glassy carbon disk electrode in plastic cylinder which can rotate at various constant speeds. The Reynolds number, a parameter, which allows to judge whether the flow is turbulent or laminar, for a RDE is given by ${ }^{107}$

$$
\operatorname{Re}=\frac{\omega r_{c}^{2}}{v}
$$


where $r_{c}$ is the radius of the cylinder, $\omega$ - the angular frequency, $v$ - the viscosity of the solution. If the Reynolds number does not exceed $10^{5}$ the flow in the solution is laminar (Fig. 6.7a). Laminar flow in the cell is a required condition for RDE electrochemical measurements.
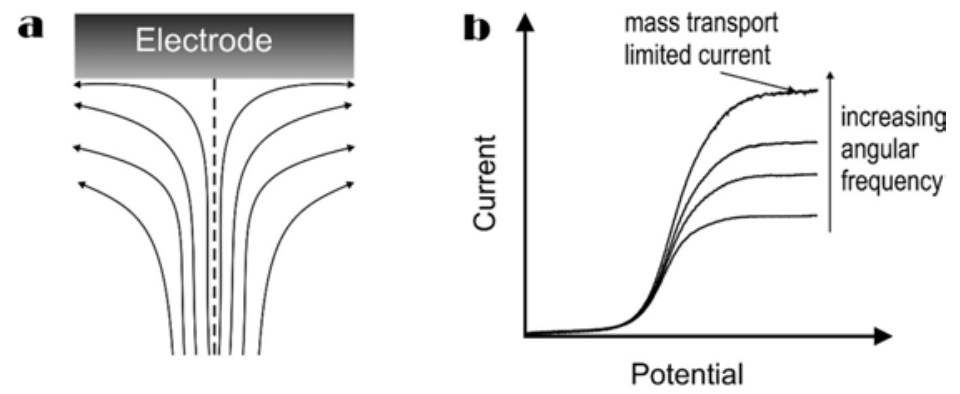

Figure 6.7. RDE measurements. a. Illustration of laminar flow, b. Current-potential curves of $\mathrm{PTZ}$ recorded in acetonitrile solution at different rotating rates.

Fig. 6.7b shows typical voltammograms obtained on a rotating disk electrode. In contrast to LSV or CV measurements on stationary electrodes no peaks are observed for the RDE. The current, and therefore the reaction rate does not decrease with increasing potential as there is no depletion effect on the RDE. The current is maintained by a convective flow of electroactive species to the electrode surface and controlled by the mass transport. This mass transportlimiting current is given by Levich equation: ${ }^{109}$

$$
I_{L}=0.62 n F A C D^{2 / 3} v^{-1 / 6} \omega^{1 / 2}
$$

where $\mathrm{C}$ - concentration of electroactive species, $v$ - the viscosity of solution.

The Levich equation was used in Paper II for the determination of the diffusion coefficient of PTZ in acetonitrile solutions.

RDE voltammetry is a convenient tool for kinetic studies of electrocatalytic reactions. The value of $\mathrm{k}_{\mathrm{s}}$ for eq. 5.2 can be determined using the following equation: ${ }^{110}$

$$
\frac{I_{c a t}}{I_{L}}=1.61\left(\frac{v}{D}\right)^{1 / 6}\left(\frac{k_{s} C}{\omega}\right)^{1 / 2}
$$

where $\mathrm{I}_{\text {cat }}$ - limiting current measured in presence of the catalytic reaction, $\mathrm{I}_{\mathrm{L}}-$ limiting current measured in absence of catalytic reaction.

RDE voltammetry was used in Paper II for calculation of catalytic rate constant of the mediated process for PTZ and GOx in acetonitrile. 


\section{Wall-jet electrode}

The wall-jet electrode used in this work was a screen-printed electrode placed in a flow-injection system so that a fine jet of solution ran into the center of the electrode and spread out radially (Fig. 6.8a,b). As can be seen from Fig. 6.8a only the solution from the incoming jet can reach the electrode surface. In flow injection systems, the analyte contacts the electrode only for a short time after injection and this leads to a peak-shaped response (Fig. 6.8c).

The flow for a wall-jet electrode is usually not completely laminar like in the case of the RDE and this leads to a more complicated dependence between current and concentration. However, the current is proportional to the concentration of the electroactive species and the technique can therefore be used for electroanalysis.

A flow injection system was used for characterization of the analytical performance and stability of glucose biosensors in Paper $\mathbf{I}$.

a
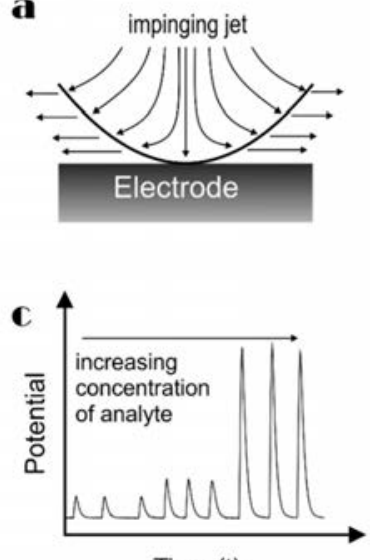

b

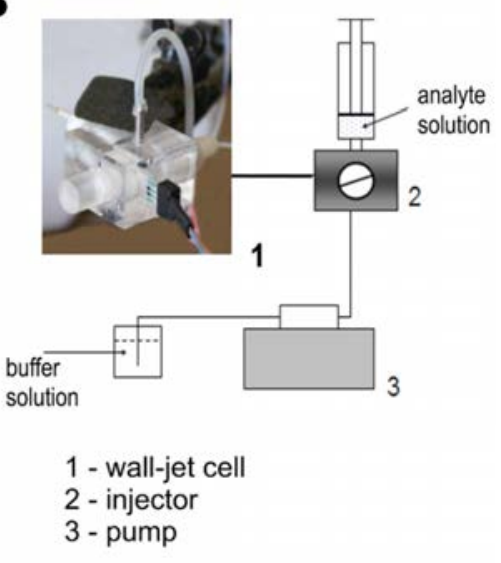

Figure. 6.8. Wall-jet electrode measurements. a. Flow pattern. b. Scheme of flowinjection system. c. Current response observed in the system.

\subsubsection{Impedance spectroscopy}

Impedance spectroscopy is a powerful method for investigation of electrical properties of electrode materials and interfaces of the electrodes. The impedance is a complex parameter of the cell when an alternating current is applied: ${ }^{9}$

$Z=\frac{U(t)}{I(t)}=|Z| e^{j \theta}=Z^{\prime}+j Z^{\prime \prime}$ 
where $\mathrm{U}(\mathrm{t})=\mathrm{U}_{\mathrm{m}} \sin (\omega \mathrm{t})$ is an alternating voltage with amplitude $\mathrm{U}_{\mathrm{m}}$ applied to the electrode, $I(t)=I_{m} \sin (\omega t-\theta)$ is the resulting current with amplitude $I_{m}, \theta$ is the phase difference between the voltage and current, $Z^{\prime}$ and $Z^{\prime \prime}$ are the real and imaginary part of the impedance, respectively, and

$j=(-1)^{1 / 2}$

$\mathrm{Z}^{\prime}$ is the normal resistance while $\mathrm{Z}^{\prime \prime}$ is called the reactance. The conductance is the inverse of the resistance. In analogy, the admittance $Y$ is often used in impedance spectroscopy and it is related to the impedance by: ${ }^{9}$

$$
Y=\frac{1}{Z}=Y^{\prime}+j Y^{\prime \prime}
$$

The most common way to perform impedance measurements, used in Paper IV, is a frequency analysis. Signals with different frequencies are applied and the amplitude and phase shift, or real and imaginary parts of the response signal are measured. The impedance data are usually presented in the complex plane plots as $-Z^{\prime \prime}$ vs $Z^{\prime}$ (Nyquist diagram) (Fig. 6.9b) or $\mathrm{Y}^{\prime \prime}$ vs $\mathrm{Y}^{\prime}$. A plot of the frequency normalized admittance components $\mathrm{Y}^{\prime} / \omega$ vs $\mathrm{Y}^{\prime \prime} / \omega$ is frequently used for investigation of non-faradaic (capacitive) processes.

Electrochemical systems can be modelled by series and parallel configurations of resistors and capacitors (Fig. 6.9a shows an example). The admittance of this particular system can be expressed as:

$$
Y=\frac{1}{R_{s}}+\frac{1}{R_{p}}\left(1+j \omega C_{d l}\right)
$$

where $R_{s}$ and $R_{p}$ are the solution and polarization resistances, respectively, $\omega$ is the angular frequency and $C_{d l}$ is the double layer capacitance (see section 2.2.1). Parameters of the equation can be determined from the impedance data plotted in the complex plane (Fig. 6.9b).

Impedance spectroscopy was used in Paper IV for the investigation of blood cell absorbance on the surface of a filament carbon cloth electrode. 


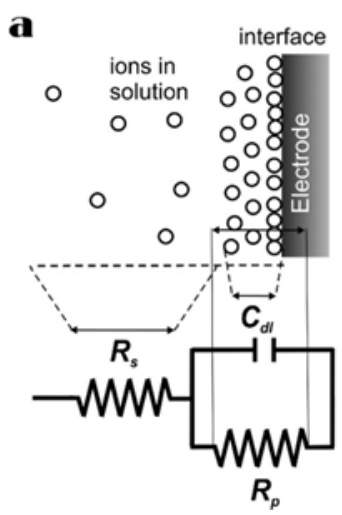

b

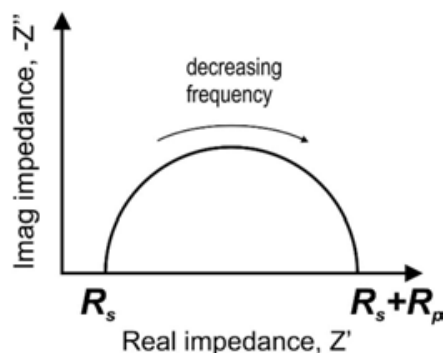

Figure. 6.9. Impedance spectroscopy. a. Simplest equivalent circuit, b. Nyquist diagram for the circuit (reproduced with modifications). ${ }^{111}$

\subsection{Optical microscopy}

Optical microscopy, with the help of digital video, is widely used for imaging of a very thin optical sections down to $0.2 \mu \mathrm{m} .{ }^{112}$ For creating a picture, a sample is illuminated with parallel rays of light along the surface normal to the sample. The rays can be scattered by the sample or pass through the sample. The light diffracted by the sample is brought to focus at various localized places on the same image plane with different intensities. These patterns of light and dark is an enlarged reconstitution of the original sample.

Optical microscopy was used for imaging of cross-sections of screen-printed microband arrays in Paper III. 


\section{7 \\ SUMMARY OF THE INCLUDED PAPERS}

The work presented in this thesis is focused on development of advanced electroanalytical devices based on mediated bioelectrocatalysis applicable for mass production.

Papers I and II are focused on studies of a new hydrophobic mediator for oxidases - unsubstituted phenothiazine. Paper I was focused on a new coimmobilization procedure to incorporate a water insoluble mediator and a hydrophilic enzyme molecule in the same membrane. We have immobilized the mediator and glucose oxidase in a sol-gel membrane from a water-organic mixture with a high content of organic solvent. The biosensor with phenothiazine as a mediator showed high long-term operational stability. In Paper II we studied the kinetics of the mediated bioelectrocatalysis of three oxidases: glucose oxidase, lactate oxidase and cholesterol oxidase by the new mediator using various electrochemical techniques: cyclic voltammetry, rotating disk electrode measurements and double-step chronoamperometry. We have shown that phenothiazine functions as an efficient mediator.

Paper III is dedicated to the development of a simple and versatile platform for scalable fabrication of electrochemical devices with advanced analytical characteristcs. We developed a simple approach for the production of graphite microband arrays suitable for automated electrode recovery. Arrays of microband electrodes were produced by screen printing followed by scissor cutting, which enabled the realization of microband arrays at the cut edge. The analytical performance of the system was investigated for detection of ascorbic acid and glucose. A microsensor based on mediated GOx was fabricated using the immobilization procedure developed in Paper I. Both systems showed enhanced sensitivity due to improved mass transport.

The efficient bioelectrocatalytic technologies developed in Papers I and II have been utilized for the fabrication of an analytical device available for autonomous measurements and scaled-up production. In Paper IV, two operational modes of the electrochemical device allow power generation and cholesterol analysis of whole plasma. 



\section{8 \\ FUTURE WORK}

The work presented in the thesis was focused on the development of new electrochemical sensors, mainly for the recognition of physiological analytes of interest in clinical chemistry. Electrochemical sensors have already made a significant impact on decentralized clinical analysis in the last decade. Yet, despite their great potential, applications of electrochemical sensors for environmental monitoring are still rather narrow.

In my future work, we are planning to focus on development of eletroanalytical systems for environmental monitoring, mainly, drinking water analysis using reagentless approaches developed in the presented work. Possible target analytes are phenolic compounds, nanoparticles, caffeine and artificial sweeteners.

The main problem of water monitoring is the low concentration of the analytes of interest. Thus, sensors used for the detection should have low detection limits and high sensitivity. We will work on improvement of these parameters using different electrode materials and configurations (microelectrodes, microelectrode arrays, microbands).

Another possible way to solve the problem of low concentration in water monitoring is the use of preconcentration techniques. However, additional preconcentration complicates and increases the cost of the analysis. In our future work, we are aiming at combining a preconcentration step with the detection. The use of molecular imprinted polymers is one of the ways to do this.

The thesis work raised some fundamental questions that will also be addressed in the future work. As can be seen from Fig. 4.4, we observed an anomalously sharp peak of the remaining enzyme activity in a water-isopropanol mixture containing $85 \%$ of isopropanol. Such enzyme behavior in water-organic mixtures was already known, but there is no explanation of this phenomenon in the literature. Using different techniques for mapping the enzyme structure and by measuring the enzymatic activity electrochemically we are expecting to find a dependence between enzyme conformation and activity. This investigation will allow us to better understand the factors influencing enzyme stability and possibly to improve the operational stability of the biosensors. 



\section{REFERENCES}

(1) D'Orazio, P. Clinica Chimica Acta 2011, 412, 1749-1761.

(2) Rodriguez-Mozaz, S.; de Alda, M. J. L.; Barcelo, D. Analytical and Bioanalytical Chemistry 2006, 386, 1025-1041.

(3) Thévenot, D. R.; Toth, K.; Durst, R. A.; Wilson, G. S. Analytical Letters 2001, 34 , 635-659.

(4) Clark, L. C.; Lyons, C. Annals of the New York Academy of Sciences 1962, 102, 2945 .

(5) May, S. W. Current Opinion in Biotechnology 1999, 10, 370-375.

(6) Solna, R.; Dock, E.; Christenson, A.; Winther-Nielsen, M.; Carlsson, C.; Emneus, J.; Ruzgas, T.; Skladal, P. Analytica Chimica Acta 2005, 528, 9-19.

(7) Brett, C. M. A.; Brett, A. M. O. Electroanalysis; Oxford Universisty Press, 1998.

(8) Золотов, Ю. А. Основы аналитической химии: В 2-х кн; Высш. шк., 1996.

(9) Scholz, F. Electroanalytical Methods: Guide to Experiments and Applications; Springer, 2009.

(10) Compton, R. G.; Wildgoose, G. G.; Rees, N. V.; Streeter, I.; Baron, R. Chemical Physics Letters 2008, 459, 1-17.

(11) Fletcher, S.; Horne, M. D. Electrochemistry Communications 1999, 1, 502-512.

(12) Wang, J.; Rogers, K. Electrochemical sensors for environmental monitoring: A review of recent technology; US Environmental Protection Agency, Office of Research and Development, Environmental Monitoring and Support Laboratory, 1995.

(13) Taylor, R. F.; Schultz, J. S. Handbook of Chemical and Biological Sensors; Taylor \& Francis, 1996.

(14) Miller, J. N.; Miller, J. C. Statistics and Chemometrics for Analytical Chemistry; Prentice Hall, 2000.

(15) McNaught, Applied, C. IUPAC compendium of chemical terminology the gold book; International Union of Pure and Applied Chemistry: [Research Triangle Park, N.C.], 2006.

(16) Shrivastava, A.; Gupta, V. Chronicles of Young Scientists 2011, 2, 21-25.

(17) Harris, D. C. Quantitative Chemical Analysis, Sixth Edition; W. H. Freeman, 2003.

(18) Turner, A. P. F. Chemical Society Reviews 2013, 42, 3184-3196.

(19) Arduini, F.; Amine, A. In Biosensors Based on Aptamers and Enzymes, Gu, M. B.; Kim, H. S., Eds., 2014, pp 299-326.

(20) Sabine Borgmann, A. S., Sebastian Neugebauer and Wolfgang Schuhmann. Amperometric Biosensors; WILEY-VCH Verlag GmbH \& Co. KGaA: Weinheim, 2011.

(21) Wang, J. Chemical reviews 2008, 108, 814-825.

(22) Wollenberger, U. Third generation biosensors-integrating recognition and transduction in electrochemical sensors; Elsevier, Amsterdam, 2005. 
(23) Ferapontova, E.; Shleev, S.; Ruzgas, T.; Stoica, L.; Christenson, A.; Tkac, J.; Yaropolov, A.; Gorton, L.; Palacek, E.; Scheller, F. Towards Electrochemical Sensors for Genomics and Proteomics 2005, 517-598.

(24) http://www.slideshare.net/biotechvictor1950/biochemical-principles-of-enzymeaction.

(25) Chang, R. Physical Chemistry for the Biosciences; University Science Books, 2005.

(26) http://www.worthington-biochem.com/introbiochem/chemNature.html.

(27) Morozova, V.; Shumakovich, G. P.; Gorbacheva, M. A.; Shleev, S. V.; Yaropolov, A. I. Biochemistry-Moscow 2007, 72, 1136-1150.

(28) Leskovac, V.; Trivic, S.; Wohlfahrt, G.; Kandrac, J.; Pericin, D. International Journal of Biochemistry \& Cell Biology 2005, 37, 731-750.

(29) Yoo, E. H.; Lee, S. Y. Sensors 2010, 10, 4558-4576.

(30) Swoboda, B. E.; Massey, V. Journal of Biological Chemistry 1965, 240, 2209 2215.

(31) Bankar, S. B.; Bule, M. V.; Singhal, R. S.; Ananthanarayan, L. Biotechnology Advances 2009, 27, 489-501.

(32) Shimomura, T.; Sumiya, T.; Ono, M.; Ito, T.; Hanaoka, T.-a. Analytica Chimica Acta 2012, 714, 114-120.

(33) Nikolaus, N.; Strehlitz, B. Microchimica Acta 2008, 160, 15-55.

(34) Jia, W. Z.; Bandodkar, A. J.; Valdes-Ramirez, G.; Windmiller, J. R.; Yang, Z. J.; Ramirez, J.; Chan, G.; Wang, J. Analytical Chemistry 2013, 85, 6553-6560.

(35) Shkotova, L. V.; Goriushkina, T. B.; Tran-Minh, C.; Chovelon, J. M.; Soldatkin, A. P.; Dzyadevych, S. V. Materials Science \& Engineering C-Biomimetic and Supramolecular Systems 2008, 28, 943-948.

(36) Kriz, K.; Kraft, L.; Krook, M.; Kriz, D. Journal of Agricultural and Food Chemistry 2002, 50, 3419-3424.

(37) Maeda-Yorita, K.; Aki, K.; Sagai, H.; Misaki, H.; Massey, V. Biochimie 1995, 77, 631-642.

(38) Iwuoha, E. I.; Rock, A.; Smyth, M. R. Electroanalysis 1999, 11, 367-373.

(39) MacLachlan, J.; Wotherspoon, A. T. L.; Ansell, R. O.; Brooks, C. J. W. Journal of Steroid Biochemistry and Molecular Biology 2000, 72, 169-195.

(40) Manjunatha, R.; Shivappa Suresh, G.; Savio Melo, J.; D'Souza, S. F.; Venkatarangaiah Venkatesha, T. Talanta 2012, 99, 302-309.

(41) Arya, S. K.; Datta, M.; Malhotra, B. D. Biosensors \& Bioelectronics 2008, 23 , 1083-1100.

(42) Silva Nunes, G.; Marty, J.-L. In Immobilization of Enzymes and Cells, Guisan, J., Ed.; Humana Press, 2006, pp 239-250.

(43) Turner, A. P. F.; Karube, I.; Wilson, G. S. Biosensors: fundamentals and applications; Oxford University Press, 1987. 
(44) Deng, C. Y.; Chen, J. H.; Nie, Z.; Si, S. H. Biosensors \& Bioelectronics 2010, 26, 213-219.

(45) Dong, S.; Kuwana, T. Electroanalysis 1991, 3, 485-491.

(46) Quinto, M.; Losito, I.; Palmisano, F.; Zambonin, C. G. Analytica Chimica Acta 2000, 420, 9-17.

(47) Fu, G. L.; Yue, X. L.; Dai, Z. F. Biosensors \& Bioelectronics 2011, 26, 3973-3976.

(48) Guisan, J. M. Immobilization of Enzymes and Cells; Humana Press, 2006.

(49) Sassolas, A.; Blum, L. J.; Leca-Bouvier, B. D. Biotechnology Advances 2012, 30 , 489-511.

(50) Braun, S.; Rappoport, S.; Zusman, R.; Avnir, D.; Ottolenghi, M. Materials Letters 1990, 10, 1-5.

(51) Tripathi, V. S.; Kandimalla, V. B.; Ju, H. Sensors and Actuators B: Chemical 2006, 114, 1071-1082.

(52) Collinson, M. M. Trac-Trends in Analytical Chemistry 2002, 21, 30-38.

(53) Pandey, P. C.; Upadhyay, S.; Pathak, H. C. Electroanalysis 1999, 11, 59-64.

(54) Lev, O.; Wu, Z.; Bharathi, S.; Glezer, V.; Modestov, A.; Gun, J.; Rabinovich, L.; Sampath, S. Chemistry of Materials 1997, 9, 2354-2375.

(55) Walcarius, A. Chemistry of Materials 2001, 13, 3351-3372.

(56) Wang, B.; Zhang, J.; Dong, S. Biosensors \& Bioelectronics 2000, 15, 397-402.

(57) Liu, S. Q.; Sun, Y. M. Biosensors \& Bioelectronics 2007, 22, 905-911.

(58) Narang, U.; Prasad, P. N.; Bright, F. V.; Ramanathan, K.; Kumar, N. D.; Malhotra, B. D.; Kamalasanan, M. N.; Chandra, S. Analytical Chemistry 1994, 66, 3139-3144.

(59) Wang, Q. L.; Lu, G. X.; Yang, B. J. Biosensors \& Bioelectronics 2004, 19, 1269 1275.

(60) Upadhyay, A. K.; Ting, T. W.; Chen, S. M. Talanta 2009, 79, 38-45.

(61) Yashina, E. I.; Borisova, A. V.; Karyakina, E. E.; Shchegolikhina, O. I.; Vagin, M. Y.; Sakharov, D. A.; Tonevitsky, A. G.; Karyakin, A. A. Analytical Chemistry 2010, 82, 1601-1604.

(62) Karyakin, A. A.; Karyakina, E. E.; Gorton, L.; Bobrova, O. A.; Lukachova, L. V.; Gladilin, A. K.; Levashov, A. V. Analytical Chemistry 1996, 68, 4335-4341.

(63) Karyakin, A. A.; Kotel'nikova, E. A.; Lukachova, L. V.; Karyakina, E. E.; Wang, J. Analytical Chemistry 2002, 74, 1597-1603.

(64) Zaks, A.; Klibanov, A. M. Journal of Biological Chemistry 1988, 263, 3194-3201.

(65) Khmelnitsky, Y. L.; Mozhaev, V. V.; Belova, A. B.; Sergeeva, M. V.; Martinek, K. European Journal of Biochemistry 1991, 198, 31-41.

(66) Schläpfer, P.; Mindt, W.; Racine, P. Clinica Chimica Acta 1974, 57, 283-289.

(67) Kulys, J.; Švirmickas, G.-J. Analytica Chimica Acta 1979, 109, 55-60.

(68) Cass, A. E.; Davis, G.; Francis, G. D.; Hill, H. A. O.; Aston, W. J.; Higgins, I. J.; Plotkin, E. V.; Scott, L. D.; Turner, A. P. Analytical Chemistry 1984, 56, 667-671. 
(69) Chaubey, A.; Malhotra, B. D. Biosensors \& Bioelectronics 2002, 17, 441-456.

(70) Nicholson, R. S.; Shain, I. Analytical Chemistry 1964, 36, 706-723.

(71) Turner, A. 1987.

(72) Dubinin, A. G.; Li, F.; Li, Y.; Yu, J. Bioelectrochemistry and Bioenergetics 1991, $25,131-135$.

(73) Jaffari, S. A.; Turner, A. P. F. Biosensors \& Bioelectronics 1997, 12, 1 -9.

(74) Shul'ga, A. A.; Koudelka-Hep, M.; de Rooij, N. F.; Netchiporouk, L. I. Analytical Chemistry 1994, 66, 205-210.

(75) Cass, A. E. G.; Davis, G.; Francis, G. D.; Hill, H. A. O.; Aston, W. J.; Higgins, I. J.; Plotkin, E. V.; Scott, L. D. L.; Turner, A. P. F. Analytical Chemistry 1984, 56, 667671.

(76) Palleschi, G.; Turner, A. P. F. Analytica Chimica Acta 1990, 234, 459-463.

(77) Turner, A. P. F., Hendry, S.P., Cardosi, M.F. In Biosensors, Instrumentation and Processing: The World Biotech Report London, 1987, pp 125-137.

(78) Murthy, A. S. N.; Anita. Biosensors \& Bioelectronics 1996, 11, 191-193.

(79) Ohara, T. J.; Rajagopalan, R.; Heller, A. Analytical Chemistry 1993, 65, 35123517.

(80) Motonaka, J.; Kamizasa, M.; Faulkner, L. R. Journal of Electroanalytical Chemistry 1994, 373, 75-81.

(81) ELDERFIELD, R. C. Heterocyclic Compounds. Edited by R.C. Elderfield; New York: Chapman \& Hall: London, 1950.

(82) Müller, D. Biochem. Z 1931, 232, 423-434.

(83) Upadhyay, A. K.; Ting, T.-W.; Chen, S.-M. Talanta 2009, 79, 38-45.

(84) Wang, Y.; Hasebe, Y. Journal of the Electrochemical Society 2012, 159, F110F118.

(85) Pereira, A. C.; Kisner, A.; Tarley, C. R. T.; Kubota, L. T. Electroanalysis 2011, 23, 1470-1477.

(86) Noorbakhsh, A.; Salimi, A.; Sharifi, E. Electroanalysis 2008, 20, 1788-1797.

(87) Liu, H.; Ying, T.; Sun, K.; Li, H.; Qi, D. Analytica Chimica Acta 1997, 344, $187-$ 199.

(88) Ohfuji, K.; Sato, N.; Hamada-Sato, N.; Kobayashi, T.; Imada, C.; Okuma, H.; Watanabe, E. Biosensors \& Bioelectronics 2004, 19, 1237-1244.

(89) Huang, Q.; An, Y.; Tang, L.; Jiang, X.; Chen, H.; Bi, W.; Wang, Z.; Zhang, W. Analytica Chimica Acta 2011, 707, 135-141.

(90) Shan, D.; Mousty, C.; Cosnier, S.; Mu, S. L. Electroanalysis 2003, 15, 1506-1512.

(91) Yao, Y.-L.; Shiu, K.-K. Electrochimica Acta 2007, 53, 278-284.

(92) Gregg, B. A.; Heller, A. Analytical Chemistry 1990, 62, 258-263.

(93) Ohara, T. J.; Rajagopalan, R.; Heller, A. Analytical Chemistry 1994, 66, 24512457. 
(94) Rubinstein, I.; Bard, A. J. Journal of the American Chemical Society 1980, 102, 6641-6642.

(95) Moyo, M.; Okonkwo, J. O.; Agyei, N. M. Sensors 2012, 12, 923-953.

(96) Arechederra, R. L.; Minteer, S. D. Analytical and Bioanalytical Chemistry 2011, 400, 1605-1611.

(97) Katz, E.; Buckmann, A. F.; Willner, I. Journal of the American Chemical Society 2001, 123, 10752-10753.

(98) Yahiro, A. T.; Lee, S. M.; Kimble, D. O. Biochimica et Biophysica Acta (BBA) Specialized Section on Biophysical Subjects 1964, 88, 375-383.

(99) Katz, E.; Willner, I.; Kotlyar, A. B. Journal of Electroanalytical Chemistry 1999, 479, 64-68.

(100) Leech, D.; Kavanagh, P.; Schuhmann, W. Electrochimica Acta 2012, 84, 223-234.

(101) Cracknell, J. A.; Vincent, K. A.; Armstrong, F. A. Chemical Reviews 2008, 108, 2439-2461.

(102) Zhou, M.; Wang, J. Electroanalysis 2012, 24, 197-209.

(103) Zhou, M.; Wang, F. A.; Dong, S. J. Electrochimica Acta 2011, 56, 4112-4118.

(104) Deng, L.; Chen, C. G.; Zhou, M.; Guo, S. J.; Wang, E. K.; Dong, S. J. Analytical Chemistry 2010, 82, 4283-4287.

(105) Meredith, M. T.; Minteer, S. D. Analytical Chemistry 2011, 83, 5436-5441.

(106) McCreery, R. L. Chemical Reviews 2008, 108, 2646-2687.

(107) Fisher, A. C. Electrode Dynamics; Oxford University Press, 1996.

(108) Aoki, K.; Tokuda, K.; Matsuda, H. Journal of electroanalytical chemistry and interfacial electrochemistry 1987, 225, 19-32.

(109) Levich, V. G. Physicochemical hydrodynamics; Prentice-Hall: Englewood Cliffs, N.J., 1962.

(110) Andrieux, C. P.; Dumasbouchiat, J. M.; Saveant, J. M. Journal of Electroanalytical Chemistry 1980, 113, 1-18.

(111) Wagner, M. Synthesis, characterisation and chemical sensor application of conducting polymers. academic dissertation, Abo Akademi University, Abo, Turku, Finland, 2013.

(112) Davidson, M. W.; Abramowitz, M. Encyclopedia of imaging science and technology. 


\section{Publications}

The articles associated with this thesis have been removed for copyright reasons. For more details about these see:

http://urn.kb.se/resolve?urn=urn:nbn:se:liu:diva-112345 